ISSN 1996-1944

www.mdpi.com/journal/materials

Article

\title{
Thermodynamic Origin of the Vitreous Transition
}

\section{Robert Tournier F.}

Centre National de la Recherche Scientifique, Université Joseph Fourier, Consortium de Recherches pour l'Emergence de Technologies Avancées, B.P. 166, 38042 Grenoble Cedex 09, France;

E-Mail: Robert.Tournier@ grenoble.cnrs.fr; Tel.: +33-608-716-878; Fax: +33-476-881-280

Received: 22 March 2011; in revised form: 19 April 2011 / Accepted: 5 May 2011 /

Published: 9 May 2011

\begin{abstract}
The vitreous transition is characterized by a freezing of atomic degrees of freedom at a temperature $\mathrm{T}_{\mathrm{g}}$ depending on the heating and cooling rates. A kinetic origin is generally attributed to this phenomenon instead of a thermodynamic one which we develop here. Completed homogeneous nucleation laws reflecting the energy saving due to Fermi energy equalization of nascent crystals and their melt are used. They are applied to bulk metallic glasses and extended to inorganic glasses and polymers. A transition $\mathrm{T}_{\mathrm{g}}$ among various $\mathrm{T}_{\mathrm{g}}$ corresponds to a crystal homogeneous nucleation temperature, leading to a preliminary formation of a cluster distribution during the relaxation time preceding the long steady-state nucleation time of crystals in small samples. The thermally-activated energy barrier $\Delta \mathrm{G}^{*}{ }_{21 \mathrm{~s}} / \mathrm{k}_{\mathrm{B}} \mathrm{T}$ at $\mathrm{T}_{\mathrm{g}}^{*}$ for homogeneous nucleation is nearly the same in all glass-forming melts and determined by similar values of viscosity and a thermally-activated diffusion barrier from melt to cluster. The glass transition $\mathrm{T}^{*} \mathrm{~g}$ is a material constant and a linear function of the energy saving associated with charge transfers from nascent clusters to the melt. The vitreous transition and the melting temperatures alone are used to predict the free-volume disappearance temperature equal to the Vogel-Fulcher-Tammann temperature of fragile glass-forming melts, in agreement with many viscosity measurements. The reversible thermodynamic vitreous transition is determined by the disappearance temperature $\mathrm{T}^{*}{ }_{\mathrm{g}}$ of the fully-relaxed enthalpy $\mathrm{H}_{\mathrm{r}}$ that is not time dependent; the observed specific heat jump at $\mathrm{T}^{*}{ }_{\mathrm{g}}$ is equal to the proportionality coefficient of $\mathrm{H}_{\mathrm{r}}$ with $\left(\mathrm{T}_{\mathrm{g}}^{*}-\mathrm{T}_{\mathrm{a}}\right.$ ) for $\mathrm{T} \leq \mathrm{T}_{\mathrm{g}}^{*}$ as expected from the enthalpy excess stored by a quenched undercooled melt at the annealing temperature $\mathrm{T}_{\mathrm{a}}$ and relaxed towards an equilibrium vitreous state. However, the heat flux measurements found in literature over the last 50 years only gave an out-of-equilibrium $T_{g}$ since the enthalpy is continuous at $\mathrm{T}_{\mathrm{g}}{ }_{\mathrm{g}}$ without visible heat jump.
\end{abstract}


Keywords: $64.70 \mathrm{kj}$ glasses; $64.70 \mathrm{P}$ glass transitions; 64.70 pe metallic glasses; $64.70 \mathrm{ph}$. non metallic glasses; 64.70 pj polymers; 64.60 Q-nucleation

\section{Introduction}

The vitreous state is described, up to now, as a freezing of liquid-state below a temperature $\mathrm{T}_{\mathrm{g}}$ called vitreous or glass transition, below which the viscosity becomes time dependent with values above $10^{12}-10^{13}$ Pa.s. This transformation at $\mathrm{T}_{\mathrm{g}}$ is also observed in the heat flow, measured with a technique of differential scanning calorimetry (DSC); endothermic and exothermic heats respectively, depending on the heating and the cooling rates, characterize glass-melt out-of-equilibrium transformations. The glass-forming melt viscosity follows a Vogel-Fulcher-Tammann (VFT) law diverging when the temperature tends to $\mathrm{T}_{0} ; \mathrm{T}_{0}$ is much smaller than $\mathrm{T}_{\mathrm{g}}$ and called the ideal glass transition temperature [1-3]. Recent work has shown that the size of heterogeneous regions simultaneously moving to allow a viscous flow grows in the vicinity of the glass transition [4]. The heterogeneous dynamics could also be the result of critical-like fluctuations of static structural order, characterized by a static correlation length diverging towards the ideal glass-transition point $T_{0}$ in the absence of a thermodynamic transition at $T_{\mathrm{g}}$. Two glass transition temperatures $\mathrm{T}_{0}$ and $\mathrm{T}_{\mathrm{g}}$ could exist without any connection between the two [5]. In addition, the residual entropy available in undercooled melt, as compared to the crystal one at the glass transition, varies strongly among glasses. The Kauzmann temperature $\mathrm{T}_{\mathrm{k}}$ has been defined as the temperature at which the crystal fusion entropy would be consumed upon cooling. It could also lead, at thermodynamic equilibrium, to a hidden phase transition following several speculations found in literature $[1,2,6]$.

The high temperature viscosity of some polymer melts, including measurements above the melting point, follows a VFT scaling law giving $\mathrm{T}_{0}=\mathrm{T}_{01}=0.77 \times \mathrm{T}_{\mathrm{g}}$ [7]. In the vicinity of the glass transition, the enthalpy relaxation times or the viscosity gives a value $T_{0}=T_{02}$ smaller than $T_{01}$. Therefore, if $T_{0}$ increases above $\mathrm{T}_{\mathrm{g}}$ within a narrow range of temperature, it explains why the viscosity values measured at high temperatures do not determine the ideal glass transition. The change of $\mathrm{T}_{0}$ occurs around the temperature $T_{s}$ where a break is seen in some volume-versus-temperature plots [8]. Many experimental results tend to prove that the ideal glass transition temperature is equal to $\mathrm{T}_{02}$ with a viscosity close to $\mathrm{T}_{\mathrm{g}}$ following a VFT law with $\mathrm{T}_{0}=\mathrm{T}_{02}$ [3]. The viscosity is an exponential function of $\mathrm{B} /\left(\mathrm{T}-\mathrm{T}_{0}\right)$ with $\mathrm{B}$ nearly proportional to $\left(\mathrm{T}_{\mathrm{g}}-\mathrm{T}_{0}\right)[9]$.

Following Doolittle's and Ramachandrarao and Dubey's works, the free-volume of glass-forming melts would disappear at the ideal glass transition temperature $\mathrm{T}_{0}[10,11]$; then, the two free-volume disappearance temperatures $\mathrm{T}_{0 \mathrm{~g}}$ and $\mathrm{T}_{0 \mathrm{~m}}$ correspond respectively to our two VFT temperatures $\mathrm{T}_{02}$ and $\mathrm{T}_{01}$ respectively. Recent numerical simulations of critical-like behavior of glass-forming melts down to $\mathrm{T}_{0}$ (assuming that the glass transition only corresponds to a slowing-down of dynamics) suggests that the melt entropy excess at equilibrium must tend to zero for $T=T_{02}=T_{0 g}$ instead of $T=T_{k}, T_{k}$ being the Kauzmann temperature [5,6,12]. New universal and coherent relations between $T_{g}, T_{0 g}=T_{02}$ and $\mathrm{T}_{0 \mathrm{~m}}=\mathrm{T}_{01}$ are proposed in this paper and checked for a series of data in real systems. The associated predictions still need to be clarified. 
The vitreous transition, observed by DSC techniques in undercooled melts, is generally time dependent and not strictly reversible, because using the same cooling and heating rates do not lead to the same transformation temperature [13]. These properties underline the kinetic aspects of the transition. A rapid cooling at temperatures far below $\mathrm{T}_{\mathrm{g}}$ followed by an annealing as a function of time at a temperature $T_{a}<T_{g}$ induces an enthalpy relaxation, saturating to a value $H_{r} ; H_{r}$ itself tends to zero for the transition temperature $\mathrm{T}^{*}$. From published values of $\mathrm{H}_{\mathrm{r}}$, it is shown that the reversible transition occurs at $\mathrm{T}_{\mathrm{g}}$, and that the transformation into the vitreous state is postponed by quenching the undercooled melt. It is achieved after a time lag equal to the relaxation time by annealing at $\mathrm{T}=\mathrm{T}_{\mathrm{a}}$. Some DSC techniques are able to separate the specific heat at $\mathrm{T}_{\mathrm{g}} \mathrm{in}$ two parts; the temperature dependent one is reversible and attached to the thermodynamic aspect of the transition, and the time dependent "irreversible" one is attached to the kinetic aspect. The reversible specific heat jump temperature measured by this technique does not depend on cooling and heating rates and is only a function of the chemical composition [13].

In this paper, we show that crystal homogeneous nucleation occurs at the glass transition $\mathrm{T}_{\mathrm{g}}$ of fragile glass-forming melts without any adjustable parameter. This nucleation only depends on the melt composition, and the obtained frozen state is a preliminary step on the long way leading to crystallization. The free energy change associated with a crystal formation in a melt has been accepted for many years, and, regardless of its radius, as if it had the same state equation as a solid outside the melt, which does not reflect the fact that the Fermi energy of a nascent crystal in a metallic melt becomes equal to that of the melt. In order to determine why the vitreous state replaces the crystallized state, a "volume energy saving" $\varepsilon_{\mathrm{v}}$ has been added to the Gibbs free-energy change associated with crystal homogeneous nucleation in melt, to obtain the equalization of Fermi energies transferring free electrons from the crystal to the melt [14-16]. The energy saving $\varepsilon_{\mathrm{v}}$ is equal to $\varepsilon_{\mathrm{lps}} \Delta \mathrm{H}_{\mathrm{m}} / \mathrm{V}_{\mathrm{m},}, \Delta \mathrm{H}_{\mathrm{m}}, \mathrm{V}_{\mathrm{m}}$, and $\varepsilon_{\mathrm{lps}}$ respectively being the molar fusion heat, the molar volume, and the energy saving coefficient, where $\varepsilon_{\text {lps }}$ is a numerical coefficient depending on the reduced temperature $\theta=\left(T-T_{m}\right) / T_{m}[16]$. The indexes $\mathrm{s}$ and 1 are related to solid and liquid states. The index $\mathrm{p}$ is suppressed for unmelted crystals acting as growth nuclei and replaced by the index $g$ for crystals resulting from homogeneous nucleation in glass-forming melts. The value of $\varepsilon_{\mathrm{lps}}$ can be predicted using the VFT temperatures $\mathrm{T}_{01}$ and $\mathrm{T}_{02}$ viewed as the disappearance temperatures $\mathrm{T}_{\mathrm{og}}$ and $\mathrm{T}_{0 \mathrm{~m}}$ of fragile-glass-forming melt free-volume and of Fermi energy difference between crystal and melt [14,15]. The vitreous transition $\mathrm{T}^{*} \mathrm{~g}$ only depends on the energy saving coefficient. The experimental values of $\mathrm{T}_{0 \mathrm{~g}}$ can also be used to predict the vitreous transition temperature $\mathrm{T}_{\mathrm{g}}^{*}$.

In this model, the crystal growth starts at the crystal nucleation temperature with a cluster preliminary formation on the long way leading to crystallization. It is locked at the vitreous transition by a freezing without any change of enthalpy and entropy. The same analysis is successfully applied to some polymers and non-metallic glass-formers. The presence of a similar "volume energy saving", governing the vitreous transition, is determined. This phenomenon is probably due to a free energy which depends on the number of molecules or atoms in a small crystal having a noncritical radius or to an electrostatic interaction between uncompensated average charges proportional to $n^{1 / 2}$ carried by nascent crystals built from a random distribution of ions on various sub-lattices and screened by ionic charges of the melt. 
This paper is built as follows: Section 2. Model; 2.1. New equations governing the crystal nucleation; 2.2. The ideal glass transition $\mathrm{T}_{0}$ and the energy saving associated with crystal formation; Section 3. Review of experimental results and discussion; 3.1 Presentation of Table 1 and Figure 1; 3.2. Homogeneous nucleation time of crystals and relaxation time; 3.3. The thermodynamic vitreous transition $\mathrm{T}_{\mathrm{g}}$ at the disappearance temperature of the fully-relaxed enthalpy; 3.4. The crystal homogeneous nucleation temperature at $\mathrm{T}_{\mathrm{g}}^{*} ; 3.5$. Volume energy saving associated with nascent crystals in non-metallic glass-forming melts; 3.6. Thermodynamic origin of the relaxed enthalpy and out-of-equilibrium transition temperatures $\mathrm{T}_{\mathrm{g}}$; Section 4. Summary and complementary information on the two crystal nucleation temperatures; Section 5. Conclusions.

\section{Model}

\subsection{New Equations Governing the Crystal Nucleation}

The classical equation describing the Gibbs free-energy change associated with a crystal formation, predicts the absence of surviving crystals above the melting temperature $T_{m}$ [17]. On the contrary, their existence is predicted far above $T_{m}$ if an energy saving per volume unit $\varepsilon_{\mathrm{v}}=\varepsilon_{\text {lps }} \times \Delta \mathrm{H}_{\mathrm{m}} / \mathrm{V}_{\mathrm{m}}$ is added. The maximum undercooling ratio $\theta_{1}=\left(\mathrm{T}_{1}-\mathrm{T}_{\mathrm{m}}\right) / \mathrm{T}_{\mathrm{m}}$ is observed as being of the order of -0.2 in liquid elements using droplet sizes of 50-10,000 micrometers instead of $-2 / 3$ [18]. This pseudo-maximum has until now been considered to be the maximum of the homogeneous nucleation rate in contradiction with a detailed study of crystallization temperature of gallium droplets as a function of their diameter. Two undercooling temperature dwells, instead of one, corresponding to $\theta_{1}=-0.28$ and $\theta_{1}=-0.5$ have been observed for diameters varying from 1 to 1,000 micrometers [19]. This phenomenon is induced by a distribution of surviving crystal radii between two boundary radii after overheating. A large overheating rate has to be applied in order to melt a part of them and obtain an undercooling rate dwell of about -0.2 [20]. The second dwell corresponding to stronger undercooling rates, is due to numerous surviving crystals having the smallest radius [21-23]. The sample radius has to be strongly reduced to observe it. The energy saving $\varepsilon_{\mathrm{v}}$ depends on the Fermi energy difference between solid and liquid and is an even function of the reduced temperature $\theta=\left(T-T_{m}\right) / T_{m}$ as shown in (1) [14,16]:

$$
\varepsilon_{\mathrm{v}}=\varepsilon_{l p s} \frac{\Delta H_{m}}{V_{m}}=\varepsilon_{l p s 0}\left(1-\frac{\theta^{2}}{\theta_{0 l p s}^{2}}\right) \frac{\Delta H_{m}}{V_{m}}
$$

Consequently, the fusion heat of unmelted crystals remains equal to $\Delta \mathrm{H}_{\mathrm{m}}$ regardless of their radius, because $\mathrm{d} \varepsilon_{1 \mathrm{~s}} / \mathrm{d} \theta=0$ and $\mathrm{d}\left(\Delta \mathrm{G}^{*}{ }_{21 \mathrm{~s}}\right) / \mathrm{d} \theta=\Delta \mathrm{H}_{\mathrm{m}} \times 4 \pi \mathrm{R}^{3} / 3 / \mathrm{V}_{\mathrm{m}}$ at $\theta=0$, with $\Delta \mathrm{G}^{*}{ }_{21 \mathrm{~s}}$ being the completed Gibbs free energy change for a crystal formation in a melt given by (2):

$$
\Delta G_{2 l p s}(R, \theta)=\frac{\Delta H_{m}}{V_{m}}\left(\theta-\varepsilon_{l p s}\right) 4 \pi \frac{R^{3}}{3}+4 \pi R^{2} \frac{\Delta H_{m}}{V_{m}}\left(1+\varepsilon_{l p s}\right)\left(\frac{12 k_{B} V_{m} \ln K_{l s}}{432 \pi \times \Delta S_{m}}\right)^{1 / 3}
$$

$\mathrm{k}_{\mathrm{B}}$ being the Boltzmann constant, $\Delta \mathrm{S}_{\mathrm{m}}$ the fusion entropy per mole and $\ln \mathrm{K}_{\mathrm{lps}}$ given by (12). The volume energy saving $\varepsilon_{\mathrm{v}}$ is added to the classical Gibbs free energy $\theta \times \Delta \mathrm{H}_{\mathrm{m}} / \mathrm{V}_{\mathrm{m}}$ and the surface energy is modified by the factor $\left(1+\varepsilon_{\mathrm{ls}}\right)$. The classical equation $\Delta \mathrm{G}_{1 \mathrm{ls}}(\theta)$ is deduced from (2) with $\varepsilon_{\mathrm{ls}}=0$ [17-19]. The experimental values of surface energy and lowest undercooling temperatures of many liquid elements have been used to determine the new surface energy and $\varepsilon_{\mathrm{ls}}$ in $(1,2)$ [17]. This 
Equation (2) allows us to calculate the unique homogeneous nucleation temperature $\theta_{2 \mathrm{ls}}=-2 / 3$ and the crystallization temperatures of liquid elements from intrinsic growth nuclei without any adjustable parameter [21-23].

The energy saving becomes equal to zero at $\mathrm{T}_{\mathrm{m}}$ above a radius a little larger than the critical radius for crystal growth nucleation to obey, at equilibrium, the classical J. W. Gibbs's phase coexistence rule and because a free electron cannot be transferred from the crystal to the melt with an energy saving larger than the Fermi energy . The crystal homogeneous nucleation maximum-rate temperature $\mathrm{T}_{2 \mathrm{ps}}$ (or $\theta_{21 \mathrm{ps}}$ ) defined by (3) in the undercooled melt is respectively called $\theta_{2 \operatorname{lgs}}$ or $\theta_{21 \mathrm{~s}}$ with values of $\varepsilon_{\operatorname{lps} 0}$ equal to $\varepsilon_{\operatorname{lgs} 0}$ or $\varepsilon_{\mathrm{ls} 0}$ :

$$
\theta_{2 l p s}=\frac{\varepsilon_{l p s}-2}{3}
$$

The $\theta_{2 \mathrm{ps}}$ only depends on the coefficient $\varepsilon_{\mathrm{lps}}$ defined by (1) and (3) and does not depend on other material properties. It is equal to $\left(\mathrm{T}_{\text {olps }}-\mathrm{T}_{\mathrm{m}}\right) / \mathrm{T}_{\mathrm{m}}$ where $\mathrm{T}_{\text {olps }}$ is equal to $\mathrm{T}_{0 \mathrm{~m}}$ or $\mathrm{T}_{0 \mathrm{~g}}$. The critical energy barrier, the critical radius and $\theta_{21 \mathrm{ps}}$ given by (3) have been calculated assuming that $\varepsilon_{\mathrm{lps}}$ is not radius dependent. This assumption works because the influence of $\mathrm{d} \varepsilon_{\mathrm{lps}} / \mathrm{dR}$ is negligible on the critical parameters of a lot of melts. Equations (1-3) have already been used to predict the time-temperature-transformation diagrams of $\mathrm{Mg}_{65} \mathrm{Y}_{10} \mathrm{Cu}_{25}, \mathrm{Zr}_{41.2} \mathrm{Ti}_{13.8} \mathrm{Cu}_{12.5} \mathrm{Ni}_{10} \mathrm{Be}_{22.5}$ and $\mathrm{Pd}_{43} \mathrm{Cu}_{27} \mathrm{Ni}_{10} \mathrm{P}_{20}$ melts [14,15] and the undercooling temperature dwells of liquid elements, in agreement with the experiments without using any adjustable parameter [21-23]. Unequal coefficients $\varepsilon_{\text {ls }} \neq \varepsilon_{\operatorname{lgs}}$ would lead to $\theta_{2 \mathrm{ls}} \neq \theta_{2 \operatorname{lgs}}$. Equal coefficients $\varepsilon_{\mathrm{lps}}=\varepsilon_{\mathrm{ls}}=\varepsilon_{\mathrm{lgs}}$ would lead to the same homogeneous nucleation temperature; the glass transition would be equal to the crystallization temperature.

\subsection{The Ideal Glass Transition Temperature $T_{0}$ and The Energy Saving Associated with}

\section{Crystal Formation}

Many experiments show the presence of numerous intrinsic growth nuclei in melts. Glasses can give rise to about $10^{25}$ nanocrystals per $\mathrm{m}^{3}$ within a few hours when they are annealed above the vitreous transition. This number is much too large to be compared with the classical homogeneous nucleation rate. High resolution microscopy reveals the existence of "mean range order" clusters called MRO with a radius of about one nanometer in amorphous $\mathrm{Fe}_{83} \mathrm{~B}_{17}$ [24]. These entities are not viewed as surviving crystals because they do not exist in the literature. They are as numerous as the nanocrystals and could be growth nuclei. A recent observation of an irreversible viscosity of $\mathrm{Fe}_{85} \mathrm{~B}_{15}$ far above the liquidus temperature could also be a sign of the existence of surviving crystals up to temperatures as high as $1.3 \mathrm{~T}_{\mathrm{m}}$ [25].

A liquid-solid transition is accompanied by Fermi energy and volume changes in metallic glass-forming melts. The free volume change $\Delta \mathrm{V}$ and the Fermi energy difference $\Delta \mathrm{E}_{\mathrm{F}}$ are expected to disappear at the same reduced temperature $\theta_{01 \mathrm{ps}}>-2 / 3$ and to be maximum at the melting temperature $(\theta=0)$ in agreement with the thermal variation given by (1) of the energy saving coefficient $\varepsilon_{\mathrm{lps}}$ of liquid elements between $\theta_{01 \mathrm{ps}}=\theta_{21 \mathrm{ps}} \cong-2 / 3$ and $\theta=0$ [14-16].

The glass-forming melt viscosity is represented by a VFT relation given by (4) depending on three parameters $\eta_{0}, B$ and $T_{0}$, in the region of the glass transition $T_{g}$ [1-3]. Its variation by several orders of 
magnitude above and close to $T_{g}$ is used to determine $T_{0}[3,26]$ because including viscosity values measured far above the melting temperature increases the $T_{0}$ value [27,28]; it is important to fix $\eta_{0} \cong \mathrm{N}_{\mathrm{A}} \times \mathrm{h} / \mathrm{V}_{\mathrm{m}}$ with $\mathrm{N}_{\mathrm{A}}$ Avogadro's number, $\mathrm{h}$ Planck's constant and $\mathrm{V}_{\mathrm{m}}$ the molar volume to evaluate $\mathrm{T}_{0}$ and $\mathrm{B}$ in (4) [28]:

$$
\eta=\eta_{0} \exp \left(\frac{B}{T-T_{0}}\right)
$$

The relaxation time dependence in the temperature range between the onset and the end of the endothermic transition is observed by DSC. At a constant heating rate, the relaxation time $\tau$ is also described by the VFT-type relation (5):

$$
\tau=\tau_{0} \exp \left(\frac{B}{T-T_{0}}\right)
$$

$\mathrm{T}_{0}$ and $\mathrm{B}$ are determined using a pre-exponential coefficient $\tau_{0}$ of about $10^{-14} \mathrm{~s}[3,27,28]$.

The free-volume of glass-forming melts is a linear function of $\left(\mathrm{T}-\mathrm{T}_{0}\right)$. Doolittle's relation introduces the free volume in the exponential of $(4,5)[10] ; \Delta \mathrm{V}$ would be equal to zero for $\mathrm{T}=\mathrm{T}_{0}$ in the absence of vitreous transition. The values of $\mathrm{T}_{0}$ would correspond to the extrapolated free-volume disappearance temperature. Some measurements exist [29,30]. For example, the $\mathrm{Pd}_{43} \mathrm{Cu}_{27} \mathrm{Ni}_{10} \mathrm{P}_{20}$ volume in the liquid and solid states are known down to an extrapolated value $\Delta \mathrm{V}=0$ occurring for $\mathrm{T}_{02} \cong 452 \mathrm{~K}$. In $\mathrm{Pd}_{40} \mathrm{Cu}_{30} \mathrm{Ni}_{10} \mathrm{P}_{20}$, the VFT law leads to $\mathrm{T}_{02}=447 \mathrm{~K}$ [31].

The minimum value of $\varepsilon_{\mathrm{lps} 0}$ in undercooled melt can be calculated only knowing $\mathrm{T}_{01}$ (or $\theta_{01}$ ) and $\mathrm{T}_{02}$ (or $\theta_{02}$ ) from VFT equations [14,15]. The quadratic equation (6) is obtained applying (1) and (3) for $\theta=\theta_{21 p s}$ :

$$
\frac{\theta_{2 l p s}^{2} \varepsilon_{l p s 0}}{\theta_{0 l p s}^{2}}+3 \theta_{2 l p s}+2-\varepsilon_{l p s 0}=0
$$

There are two solutions for $\theta_{21 \mathrm{ps}}$ when $\varepsilon_{\mathrm{lps} 0}$ is larger than a minimum value as already described [14,15]. The relations (7) and (8) between $\varepsilon_{\mid \mathrm{ps} 0}, \theta_{2 \mathrm{lps}}$ and $\theta_{0 l p s}^{2}$ are respected when the double solution corresponds to a minimum value of $\varepsilon_{\text {lps } 0}$ larger than 1 . It is given by $(7,8)$ and occurs when $9-4 \times\left(2-\varepsilon_{\text {lps } 0}\right) \times \varepsilon_{\text {lps } 0} / \theta^{2}{ }_{01 p s}=0$ :

$$
\begin{gathered}
\varepsilon_{l p s 0}=\varepsilon_{l p s}(\theta=0)=1.5 \times \theta_{2 l p s}+2 \\
\theta_{0 l p s}^{2}=\frac{8}{9} \varepsilon_{l p s 0}-\frac{4}{9} \varepsilon_{l p s 0}^{2}
\end{gathered}
$$

The knowledge of $\theta_{02}$ and $\theta_{01}$ from VFT equations chosen respectively equal to $\theta_{0 \operatorname{lgs}}$ and $\theta_{01 \mathrm{~s}}$ and the use of (7) or (8) determine $\varepsilon_{\mathrm{lps} 0}$ and $\theta_{2 \mathrm{lps}}$ and the minimum value of $\varepsilon_{\mathrm{lps} 0}$. The existence of two glass-former classes and their boundaries are predicted completing Angel's description, if we assume that $\theta_{2 \operatorname{lgs}}=\theta_{\mathrm{g}}=\left(\mathrm{T}^{*} \mathrm{~g}_{\mathrm{m}}-\mathrm{T}_{\mathrm{m}}\right) / \mathrm{T}_{\mathrm{m}}[3]$.

Fragile bulk glasses correspond to $\theta_{0 \mathrm{lgs}}=\theta_{0 \mathrm{~g}}>-2 / 3$ and $\varepsilon_{\operatorname{lgs} 0}>1$, and fragile and quenched glasses to $\varepsilon_{\operatorname{lgs} 0}<1$ and $\theta_{2 \operatorname{lgs}}=\theta_{0 \mathrm{~g}}=-2 / 3$. The undercooled liquid state can be recovered by heating the glass above $\mathrm{T}_{2 \operatorname{lgs}}$ (or $\theta_{2 \operatorname{lgs}}$ ) because the condition $\varepsilon_{\operatorname{lgs} 0}>1$ stabilizes it. It is not recovered when $\varepsilon_{\operatorname{lgs} 0}<1$ and $\theta_{0 \mathrm{~g}}=-2 / 3$ because there is no minimum value of $\varepsilon_{\operatorname{lgs} 0}$. All predictions of $(7,8)$ are related to the 
free-volume disappearance temperature of fragile undercooled melts which is equal to the ideal glass transition temperature. Angel's classification does not fix a quantified boundary between strong and fragile ones.

The strong glass-forming melts correspond to $\theta_{0 \operatorname{lgs}} \leq-2 / 3, \varepsilon_{\operatorname{lgs} 0}<2$, and $\theta_{2 \operatorname{lgs}}>-2 / 3$. They also have a viscosity larger than fragile melts with temperature dependence close to Arrhenius law. Their vitreous transition temperature can be a very large fraction of the melting temperature. The largest value of $\varepsilon_{\mathrm{lps} 0}$ is deduced from the experimental values of $\theta_{01 \mathrm{ps}}$ and $\theta_{2 \mathrm{lps}}$ using (6). Strong glass-forming melts have a homogeneous nucleation temperature always larger than $T_{m} / 3$ without metastable values of $\varepsilon_{\mathrm{lps} 0}$ regardless of the energy saving.

\section{Review of Experimental Results and Discussion}

\subsection{Presentation of Table 1 and Figure 1}

The melting temperatures $\mathrm{T}_{\mathrm{m}}$, the experimental glass transition temperatures $\mathrm{T}_{\mathrm{g}}$ or $\theta_{\mathrm{g}}=\left(\mathrm{T}_{\mathrm{g}}-\mathrm{T}_{\mathrm{m}}\right) / \mathrm{T}_{\mathrm{m}}$, the VFT temperatures $\mathrm{T}_{01}$ determined up to temperatures much higher than $\mathrm{T}_{\mathrm{g}}$, the VFT temperatures $T_{02}$ determined by viscosity or relaxation time measurements in the vicinity of $T_{m}$, the free-volume disappearance temperatures $\mathrm{T}_{0 \mathrm{~g}}=\mathrm{T}_{0 \mathrm{lgs}}$ calculated using $(7,8)$ and $(18)$ considering that $\mathrm{T}_{\mathrm{g}}$ is, in a first approximation, nearly equal to the thermodynamic glass nucleation temperature $\mathrm{T}_{\mathrm{g}}$, the saving energy coefficients $\varepsilon_{\mathrm{ls} 0}(\theta=0)$ of crystals surviving in the melt far above $\mathrm{T}_{\mathrm{g}}$ calculated using (19), the saving energy coefficients $\varepsilon_{\operatorname{lgs} 0}(\theta=0)$ of nascent crystals homogeneously nucleated in the melt near $\mathrm{T}_{\mathrm{g}}$ calculated using (18), the free-volume disappearance temperatures $\mathrm{T}_{0 \mathrm{~m}}=\mathrm{T}_{01}$ calculated using $(7,8,19,20), \mathrm{T}_{\mathrm{g}}$, and the references [32-63] are given in Table 1.

Properties of 20 non-metallic glasses and polymers are numbered with references. $\mathrm{B}_{2} \mathrm{O}_{3}$ is numbered 11 and 12. Two values of $\mathrm{T}_{\mathrm{g}}$ are used. This glass is not easily crystallized. It gives rise to

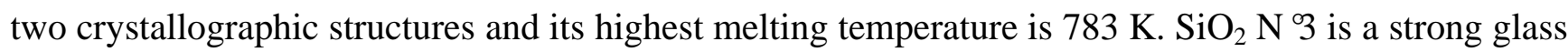
$\left(\theta_{01}<-0.666\right)$. Hevea rubber $N^{\circ} 50$ is just at the limit separating strong glasses from fragile ones because $\mathrm{T}_{\mathrm{og}}$ is a little larger than $\mathrm{T}_{\mathrm{m}} / 3$.

Properties of 28 bulk metallic glasses are used and numbered with references. The difference of liquidus and solidus temperatures is sometimes too large. A homogeneous melt has a well-defined Fermi energy. The melting temperature has been chosen between these two limits looking at the DSC profile. Two melting temperatures $\mathrm{T}_{\mathrm{m}}=728 \mathrm{~K}$ and $\mathrm{T}_{1}=925 \mathrm{~K}$ are used for $\mathrm{La}_{55} \mathrm{Al}_{25} \mathrm{Ni}_{20} \mathrm{~N}^{\circ} 21$ and 22. The first one corresponds to the largest endothermic peak and the second one to the liquidus. We find $\varepsilon_{\mathrm{ls} 0}=1.65$ and about 1.51 respectively. Two melting temperatures are also used for $\mathrm{Pd}_{40} \mathrm{Ni}_{40} \mathrm{P}_{20} \mathrm{~N}^{\circ} 24$ and $25, \mathrm{~T}_{\mathrm{m}}=987 \mathrm{~K}$ and $\mathrm{T}_{\mathrm{m}}=884 \mathrm{~K}$ leading to $\varepsilon_{\mathrm{ls} 0}=1.63$ and 1.56 respectively. The melting temperatures of $\mathrm{La}_{55} \mathrm{Al}_{25} \mathrm{Ni}_{5} \mathrm{Cu}_{15} \mathrm{~N}^{\circ} 28, \mathrm{La}_{55} \mathrm{Al}_{25} \mathrm{Ni}_{15} \mathrm{Cu}_{5} \mathrm{~N}^{\circ} 32$ and $\mathrm{La}_{55} \mathrm{Al}_{25} \mathrm{Ni}_{5} \mathrm{Cu}_{10} \mathrm{Co}_{5} \mathrm{~N}^{\circ} 41$ are respectively chosen equal to $700 \mathrm{~K}$ instead of $878 \mathrm{~K}, 729 \mathrm{~K}$ instead of $899 \mathrm{~K}$ and $754 \mathrm{~K}$ instead of $822.5 \mathrm{~K}$.

Experimentalists call all glasses characterized by a crystallization temperature $T_{x}$ occurring near $T_{g}$ "conventional". Among them, glasses have a value of $\mathrm{T}_{\mathrm{g}}$ close to $\mathrm{T}_{\mathrm{m}} / 2$. The glass transitions of $\mathrm{Al}_{87} \mathrm{Co}_{4} \mathrm{Ce}_{9}, \mathrm{Al}_{87} \mathrm{Co}_{6} \mathrm{Ce}_{7}, \mathrm{Al}_{87} \mathrm{Co}_{8} \mathrm{Ce}_{5}, \mathrm{Al}_{85} \mathrm{Co}_{10} \mathrm{Ce}_{5}$ and $\mathrm{Al}_{90} \mathrm{Co}_{5} \mathrm{Ce}_{5}$ are not reported because they cannot be distinguished from the crystallization temperature $\mathrm{T}_{\mathrm{x}}$, in the absence of endothermic heat before crystallization in a DSC run [62]. The values of $\left.\theta_{x}=\left(T_{x}-T_{m}\right) / T_{m}\right)$ are respectively equal to 
$-0.481,-0.523,-0.533,-0.543,-0.567 . \mathrm{Au}_{0.77} \mathrm{Ge}_{0.136} \mathrm{Si}_{0.094} \mathrm{~N}^{\circ} 51$ is characterized by a crystallization temperature $\mathrm{T}_{\mathrm{x}}$ occurring above and very close to $\mathrm{T}_{\mathrm{g}}$ with $\theta_{\mathrm{g}}=-0.539$ [63]. All these alloys have an energy saving coefficient larger than 1 . They could belong to the fragile glass class because they have a VFT temperature $T_{0}$ larger than $T_{m} / 3$.

Table 1. Some properties of 46 glass-forming melts are presented: $T_{m}$ the melting temperature; $T_{g}$ the vitreous transition temperature, $\theta_{g}=\left(T_{g}-T_{m}\right) / T_{m}, T_{01}$ and $T_{02}$ the Vogel-Fulcher-Tammann temperatures, as found in various references; $\mathrm{T}_{0 \mathrm{~g}}$ the free-volume disappearance temperature calculated from $\mathrm{T}_{\mathrm{g}}$ and not from $\mathrm{T}_{\mathrm{g}} ; \varepsilon_{\mathrm{ls} 0}$ the energy saving coefficient of tiny crystals surviving in the melt and acting as growth nuclei; $\varepsilon_{\operatorname{lgs} 0}$ the energy saving coefficient of homogeneously-nucleated crystals in the melt; $\varepsilon_{\mathrm{ls} 0}$ and $\varepsilon_{\operatorname{lgs} 0}$ being used to calculate $\mathrm{T}_{0 \mathrm{~m}}$ and $\mathrm{T}_{0 \mathrm{~g}} ; \mathrm{T}_{0 \mathrm{~m}}$ the free-volume disappearance temperature also calculated from $\mathrm{T}_{\mathrm{g}}$ and not from $\mathrm{T}_{\mathrm{g}}$; and references.

\begin{tabular}{|c|c|c|c|c|c|c|c|c|c|c|c|}
\hline & Glass & $\mathbf{T}_{\mathbf{m}}$ & $\mathbf{T}_{\mathrm{g}}$ & $\theta_{\mathrm{g}}$ & $\mathbf{T}_{01}$ & $\mathbf{T}_{\mathbf{0 2}}$ & $\mathbf{T}_{\mathbf{0 g}}$ & $\varepsilon_{\text {ls0 }}$ & $\varepsilon_{\operatorname{lgs} 0}$ & $\mathbf{T}_{\mathbf{0 m}}$ & References \\
\hline 1 & $\mathrm{As}_{2} \mathrm{~S}_{3}$ & 585 & 481 & -0.178 & & 270 & 319 & 1.822 & 1.732 & 363 & {$[32,33]$} \\
\hline 2 & Propylene glycol & 214 & 167 & -0.220 & & 117 & 108 & 1.780 & 1.671 & 125 & {$[26,34,35]$} \\
\hline 3 & $\mathrm{SiO}_{2}$ & 1,993 & 1,473 & -0.261 & & 300 & & & 1.36 & & {$[2,36]$} \\
\hline 4 & Propylene carbonate & 217 & 160 & -0.263 & 130 & & 102 & 1.737 & 1.606 & 119 & [35] \\
\hline 5 & polystyrene & 513 & 375 & -0.269 & 323 & & 239 & 1.731 & 1.596 & 280 & {$[26,37]$} \\
\hline 6 & $\mathrm{Pd}_{43} \mathrm{Ni}_{10} \mathrm{Cu}_{27} \mathrm{P}_{20}$ & 802 & 585 & -0.271 & 452 & & 372 & 1.729 & 1.594 & 436 & {$[29,38,39]$} \\
\hline 7 & O-Terphenil & 329 & 240 & -0.271 & 208 & & 153 & 1.729 & 1.593 & 179 & {$[3,26,40]$} \\
\hline 8 & $\mathrm{Pd}_{40} \mathrm{Cu}_{30} \mathrm{Ni}_{10} \mathrm{P}_{20}$ & 823 & 578 & -0.298 & 447 & & 366 & 1.702 & 1.553 & 432 & {$[29,31,39]$} \\
\hline 9 & Salol & 315 & 220 & -0.302 & 183 & & 139 & 1.698 & 1.548 & 165 & {$[3,26,35]$} \\
\hline 10 & $\mathrm{As}_{2} \mathrm{Se}_{3}$ & 645 & 450 & -0.302 & 335 & & 285 & 1.698 & 1.547 & 337 & {$[41]$} \\
\hline 11 & $\mathrm{~B}_{2} \mathrm{O}_{3}$ & 783 & 545 & -0.304 & 402 & & 345 & 1.696 & 1.544 & 408 & {$[3,11,32]$} \\
\hline 12 & $\mathrm{~B}_{2} \mathrm{O}_{3}$ & 783 & 521 & -0.335 & & 263 & 330 & 1.665 & 1.498 & 393 & {$[3,11,32]$} \\
\hline 13 & Bromopentane & 158 & 107 & -0.323 & 74 & & 68 & 1.677 & 1.516 & 80 & {$[26]$} \\
\hline 14 & $\mathrm{ZnCl}_{2}$ & 565 & 380 & -0.327 & 274 & & 241 & 1.673 & 1.509 & 286 & {$[2,26]$} \\
\hline 15 & Butene 1 & 88 & 59 & -0.330 & & & 37 & 1.670 & 1.506 & 44 & [2] \\
\hline 16 & $\mathrm{Zr}_{41.2} \mathrm{Ti}_{13.8} \mathrm{Cu}_{12.5} \mathrm{Ni}_{10} \mathrm{Be}_{22.5}$ & 937 & 625 & -0.333 & 413 & & 396 & 1.667 & 1.501 & 472 & {$[39,42]$} \\
\hline 17 & $\mathrm{La}_{55} \mathrm{Al}_{25} \mathrm{Ni}_{10} \mathrm{Cu}_{10}$ & 662 & 441 & -0.334 & & 255 & 280 & 1.666 & 1.499 & 333 & [43-45] \\
\hline 18 & 2 Methylpentane & 120 & 80 & -0.338 & 58 & & 50 & 1.663 & 1.494 & 60 & {$[2,26,46]$} \\
\hline 19 & Toluene & 178 & 117 & -0.343 & 104 & & 74 & 1.657 & 1.485 & 89 & {$[47]$} \\
\hline 20 & Glycerol & 293 & 190 & -0.352 & & 128 & 121 & 1.648 & 1.473 & 144 & {$[26,34,35]$} \\
\hline 21 & $\mathrm{La}_{55} \mathrm{Al}_{25} \mathrm{Ni}_{20}$ & 728 & 470 & -0.354 & & 307 & 299 & 1.646 & 1.469 & 358 & {$[43-45]$} \\
\hline 22 & $\mathrm{La}_{55} \mathrm{Al}_{25} \mathrm{Ni}_{20}$ & 925 & 470 & -0.492 & & 309 & 330 & 1.508 & 1.262 & 394 & [43-45] \\
\hline 23 & $\mathrm{PET}=\left(\mathrm{C}_{10} \mathrm{H}_{8} \mathrm{O}_{4}\right) \mathrm{n}$ & 542 & 342 & -0.369 & & & 219 & 1.631 & 1.446 & 262 & [2] \\
\hline 24 & $\mathrm{Pd}_{40} \mathrm{Ni}_{40} \mathrm{P}_{20}$ & 884 & 554 & -0.373 & & 356 & 355 & 1.627 & 1.440 & 425 & {$[48,49]$} \\
\hline 25 & $\mathrm{Pd}_{40} \mathrm{Ni}_{40} \mathrm{P}_{20}$ & 987 & 554 & -0.439 & & 356 & 369 & 1.561 & 1.342 & 442 & {$[48,49]$} \\
\hline 26 & $\mathrm{Pt}_{57.5} \mathrm{Cu}_{14.7} \mathrm{Ni}_{5.3} \mathrm{P}_{22.5}$ & 813 & 509 & -0.374 & & 336 & 326 & 1.626 & 1.439 & 390 & {$[50]$} \\
\hline 27 & $\mathrm{Pd}_{0.775} \mathrm{Cu}_{0.06} \mathrm{Si}_{0.165}$ & 1,015 & 632 & -0.377 & 515 & & 405 & 1.623 & 1.434 & 486 & {$[51]$} \\
\hline 28 & $\mathrm{La}_{55} \mathrm{Al}_{25} \mathrm{Ni}_{5} \mathrm{Cu}_{15}$ & 700 & 436 & -0.378 & & 286 & 279 & 1.622 & 1.433 & 335 & [43-45] \\
\hline 29 & $\mathrm{Zr}_{52.5} \mathrm{Cu}_{17.9} \mathrm{Ni}_{14.6} \mathrm{Al}_{10} \mathrm{Ti}_{5}$ & 1,090 & 675 & -0.381 & 521 & & 434 & 1.619 & 1.429 & 519 & {$[52]$} \\
\hline
\end{tabular}


Table 1. Cont.

\begin{tabular}{|c|c|c|c|c|c|c|c|c|c|c|c|}
\hline & Glass & $\mathbf{T}_{\mathbf{m}}$ & $\mathbf{T}_{\mathbf{g}}$ & $\theta_{\mathrm{g}}$ & $\mathbf{T}_{01}$ & $\mathbf{T}_{\mathbf{0 2}}$ & $\mathbf{T}_{\mathbf{0 g}}$ & $\varepsilon_{\mathrm{ls} 0}$ & $\varepsilon_{\text {lgs0 }}$ & $\mathbf{T}_{\mathbf{0 m}}$ & References \\
\hline 30 & $\mathrm{Pt}_{57.3} \mathrm{Cu}_{14.6} \mathrm{Ni}_{5.3} \mathrm{P}_{22.8}$ & 788 & 487 & -0.382 & & 336 & 313 & 1.618 & 1.427 & 375 & {$[50]$} \\
\hline 31 & $\mathrm{Se}$ & 491 & 303 & -0.383 & 220 & & 195 & 1.617 & 1.426 & 233 & {$[2,53]$} \\
\hline 32 & $\mathrm{La}_{55} \mathrm{Al}_{25} \mathrm{Ni}_{15} \mathrm{Cu}_{5}$ & 729 & 449 & -0.384 & & 273 & 289 & 1.616 & 1.424 & 346 & [43-45] \\
\hline 33 & $\mathrm{Au}_{49} \mathrm{Ag}_{5.5} \mathrm{Pd}_{2.3} \mathrm{Cu}_{26.9} \mathrm{Si}_{16.3}$ & 655 & 403 & -0.385 & & 250 & 259 & 1.615 & 1.423 & 311 & [39] \\
\hline 34 & Ethanol & 159 & 97 & -0.390 & 78 & 58 & 63 & 1.610 & 1.415 & 75 & {$[2,11,32]$} \\
\hline 35 & $\mathrm{Zr}_{58.5} \mathrm{Cu}_{15.6} \mathrm{Ni}_{12.8} \mathrm{Al}_{10.3} \mathrm{Nb}_{2.8}$ & 1,110 & 673 & -0.394 & & 437 & 435 & 1.606 & 1.409 & 522 & {$[54]$} \\
\hline 36 & $\mathrm{Zr}_{57} \mathrm{Cu}_{15.4} \mathrm{Ni}_{12.6} \mathrm{Al}_{10.3} \mathrm{Nb}_{5}$ & 1,120 & 678 & -0.395 & 525 & & 438 & 1.605 & 1.408 & 526 & {$[52]$} \\
\hline 37 & $\operatorname{Pr}_{55} \mathrm{Ni}_{25} \mathrm{Al}_{20}$ & 820 & 494 & -0.398 & & 296 & 320 & 1.602 & 1.404 & 384 & [55] \\
\hline 38 & $\mathrm{Ti}_{41.5} \mathrm{Cu}_{37.5} \mathrm{Ni}_{7.5} \mathrm{Zr}_{2.5} \mathrm{Hf}_{5} \mathrm{Sn}_{5} \mathrm{Si}_{1}$ & 1,176 & 693 & -0.411 & & & 452 & 1.589 & 1.384 & 543 & {$[56]$} \\
\hline 39 & $\mathrm{Cu}_{47} \mathrm{Ti}_{34} \mathrm{Zr}_{11} \mathrm{Ni}_{8}$ & 1,144 & 673 & -0.412 & 500 & & 439 & 1.588 & 1.382 & 527 & [57] \\
\hline 40 & $\mathrm{Y}_{56} \mathrm{Al}_{24} \mathrm{Co}_{20}$ & 1,085 & 636 & -0.414 & 614 & & 416 & 1.586 & 1.379 & 499 & {$[58]$} \\
\hline 41 & $\mathrm{La}_{55} \mathrm{Al}_{25} \mathrm{Ni}_{5} \mathrm{Cu}_{10} \mathrm{Co}_{5}$ & 754 & 439 & -0.418 & & 241 & 288 & 1.582 & 1.374 & 345 & [43-45] \\
\hline 42 & $\mathrm{Mg}_{59.5} \mathrm{Cu}_{22.9} \mathrm{Ag}_{6.6} \mathrm{Gd}_{11}$ & 734 & 425 & -0.421 & & 249 & 279 & 1.579 & 1.369 & 335 & [59] \\
\hline 43 & $\mathrm{Mg}_{61} \mathrm{Cu}_{28} \mathrm{Gd}_{11}$ & 737 & 422 & -0.427 & & 256 & 278 & 1.573 & 1.359 & 334 & [59] \\
\hline 44 & $\mathrm{Mg}_{65} \mathrm{Cu}_{25} \mathrm{Y}_{10}$ & 739 & 400 & -0.459 & 363 & 260 & 271 & 1.541 & 1.312 & 325 & [27] \\
\hline 45 & $\mathrm{Zr}_{46.75} \mathrm{Ti}_{8.25} \mathrm{Cu}_{7.5} \mathrm{Ni}_{10} \mathrm{Be}_{27.5}$ & 1,070 & 595 & -0.444 & & 372 & 398 & 1.556 & 1.334 & 477 & [60] \\
\hline 46 & Cyclo-octanol & 298 & 165 & -0.446 & & 92 & 110 & 1.554 & 1.331 & 133 & {$[26]$} \\
\hline 47 & $\mathrm{Zr}_{65} \mathrm{Al}_{10} \mathrm{Ni}_{10} \mathrm{Cu}_{15}$ & 1,161 & 641 & -0.448 & & 437 & 430 & 1.552 & 1.328 & 516 & {$[39]$} \\
\hline 48 & $\mathrm{Ce}_{60} \mathrm{Al}_{10} \mathrm{Ni}_{10} \mathrm{Cu}_{20}$ & 677 & 373 & -0.449 & 331 & & 250 & 1.551 & 1.326 & 300 & {$[61]$} \\
\hline 49 & $\mathrm{Al}_{87} \mathrm{Co}_{4} \mathrm{Ce}_{9}$ & 1,104 & 573 & -0.481 & & & 397 & 1.519 & 1.279 & 475 & {$[62]$} \\
\hline 50 & Hevea rubber & 421 & 200 & -0.525 & & 136 & 147 & 1.475 & 1.213 & 174 & {$[32]$} \\
\hline 51 & $\mathrm{Au}_{0.77} \mathrm{Ge}_{0.136} \mathrm{Si}_{0.094}$ & 629 & 290 & -0.539 & 241 & & 217 & 1.461 & 1.192 & 257 & {$[63]$} \\
\hline
\end{tabular}

Figure 1. The VFT temperatures $\mathrm{T}_{01}$ and $\mathrm{T}_{02}$ given in Table 1 are plotted versus $\mathrm{T}_{\mathrm{g}} ; \mathrm{T}_{02}$ corresponds to measurements in the vicinity of $\mathrm{T}_{\mathrm{g}}$ and $\mathrm{T}_{01}$ includes viscosity measurements at higher temperatures. $\mathrm{T}_{01} \cong 0.787 \mathrm{~T}_{\mathrm{g}}$ and $\mathrm{T}_{02} \cong 0.634 \mathrm{~T}_{\mathrm{g}}$.

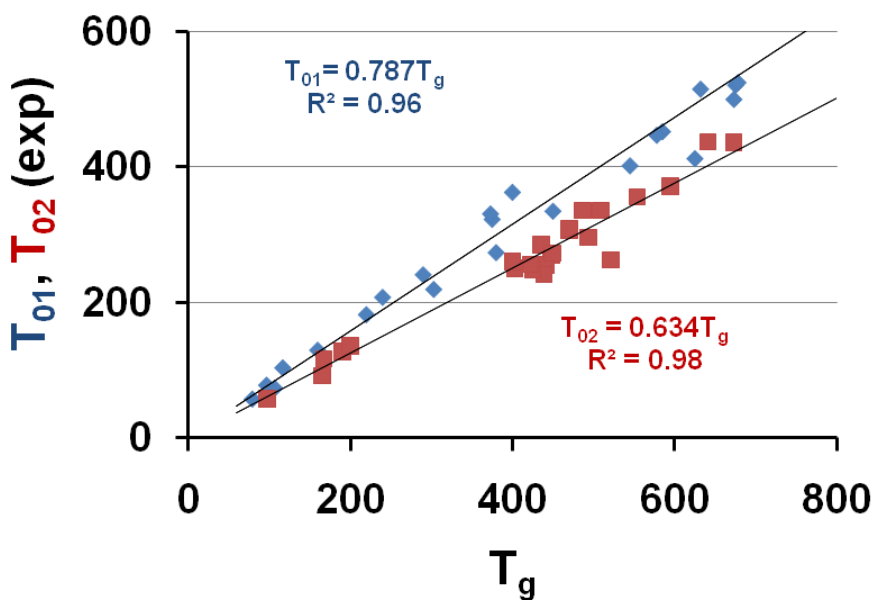

The temperatures $T_{01}$ and $T_{02}$ are plotted as a function of the vitreous transition temperature $T_{g}$ in Figure 1; the upper straight line uses the equation $\mathrm{T}_{01}=0.787 \times \mathrm{T}_{\mathrm{g}}$ and corresponds to a similar law $\mathrm{T}_{01}=0.77 \times \mathrm{T}_{\mathrm{g}}$ already observed for 7 other polymers [7,64]; the lower straight line uses the equation $\mathrm{T}_{02}=0.634 \times \mathrm{T}_{\mathrm{g}}$. 


\subsection{Homogeneous Nucleation Temperature of Vitreous Phase and Relaxation Time}

The calculation of the crystal nucleation full time $t$ includes not only the steady-state nucleation time $t_{\mathrm{sn}}$ defined by $\mathrm{v} \times \mathrm{t}_{\mathrm{sn}}=1$ in (10) at the nucleation temperature, but also the time lag $\tau^{\mathrm{ns}}$ in crystal transient nucleation defined by (9) [2] with $\mathrm{K}_{\operatorname{lgs}}$ defined by (12):

$$
\begin{gathered}
\tau^{n s}=\frac{a_{0}^{*}}{2 \pi \Gamma K_{\lg s}} \\
\ln \left(J \mathrm{v} t_{s n}\right)=\ln \left(K_{\lg s} \mathrm{v} t_{s n}\right)-\frac{\Delta G_{2 \lg s}^{*}}{k_{B} T} \\
J \tau^{n s}=\frac{\pi N}{12 \Gamma} \exp \left(-\frac{\Delta G_{2 \lg s}^{*}}{k_{B} T}\right) \\
\ln \left(K_{\lg s}\right)=\ln \left(\frac{A \eta_{0}}{\eta}\right)=(\ln A) \pm 2-\frac{B}{\left(T-T_{0 g}\right)}
\end{gathered}
$$

The steady-state nucleation rate is $\mathrm{J}$, the volume sample $\mathrm{v}$, Zeldovitch's factor $\Gamma$, the critical energy barrier $\Delta \mathrm{G}^{*}{ }_{2 \operatorname{lgs}} / \mathrm{k}_{\mathrm{B}} \mathrm{T}, \mathrm{a}^{*}{ }_{0}=\pi^{2} / 6$, the atom or molecule number per volume unit $\mathrm{N}$. The quantity $\ln \mathrm{K}_{\mathrm{ls}}$ is equal to $\ln \mathrm{A} \cong 90 \pm 2$ for liquid elements in a broad temperature scale; $\ln \mathrm{A}$ is a little smaller for crsystallization of glass-forming melts. In the vicinity of $\mathrm{T}_{\mathrm{g}}$, and assuming that $\mathrm{T}_{\mathrm{g}}\left(\right.$ or $\left.\theta^{*} \mathrm{~g}\right)$ is equal to a crystal homogeneous nucleation temperature $\mathrm{T}_{2 \operatorname{lgs}}$ (or $\theta_{2 \operatorname{lgs}}$ ), when $\mathrm{J}=1$, the crystal transient nucleation time $\tau^{\text {ns }}$ viewed as the relaxation time, can be calculated with (15) using the critical parameters (13) and (14):

$$
\begin{gathered}
\frac{\Delta G_{2 \lg s}^{*}}{K_{B} T}=\frac{12}{81} \frac{\left(1+\varepsilon_{\lg s}\right)^{3}}{\left(\theta-\varepsilon_{\lg s}\right)^{2}} \frac{\ln K_{\lg s}}{(1+\theta)} \\
R_{2 l s}^{*}(\theta)=\frac{-2\left(1+\varepsilon_{\lg s}\right)}{\theta-\varepsilon_{\lg s}}\left(\frac{V_{m}}{N_{A}}\right)^{1 / 3}\left(\frac{12 k_{B} V_{m} \ln K_{\lg s}}{432 \pi \times \Delta S_{m}}\right)^{1 / 3} \\
\tau^{n s}=\frac{\pi N}{12 \Gamma} \exp \left(-\ln K_{\lg s}\right)=\frac{\pi N}{12 \Gamma} \exp \left(-\ln A_{g}\right) \times \exp \left(\frac{B}{T-T_{0 g}}\right)=\tau_{0} \exp \left(\frac{B}{T-T_{0 g}}\right)
\end{gathered}
$$

The coefficient of $\ln K_{\mathrm{lgs}}$ in (13) is equal to 1 for $\theta=\theta_{2 \mathrm{lgs}}=\left(\varepsilon_{\mathrm{ls}}-2\right) / 3$ when the crystal-steady-state nucleation time is minimum. The $\mathrm{A}_{\mathrm{g}}$ is the A value defined by (12) at the glass transition, which is used for the homogeneously-nucleated cluster formation. Zeldovitch's factor given by (16) is calculated below, as a function of the number $\mathrm{J}_{\mathrm{c}}$ of molecules or atoms in a spherical crystal of critical radius $\mathrm{R} *_{2 \operatorname{lgs}}$, given by (14) at $\theta_{2 \operatorname{lgs}}=\theta *_{\mathrm{g}}$. The pre-exponential time $\tau_{0}$ given by (17) depends on $\mathrm{A}_{\mathrm{g}}$ and $\ln \left(\tau^{\mathrm{ns}} / \tau_{0}\right)$ is equal to $\mathrm{B} /\left(\mathrm{T}_{\mathrm{g}}^{*}-\mathrm{T}_{0 \mathrm{~g}}\right) \cong 36.5-39$ at $\mathrm{T}_{\mathrm{g}}^{*}[3,9]$ :

$$
\begin{gathered}
\Gamma=\left(\frac{\ln K_{\lg s}}{3 \pi}\right)^{1 / 2} \frac{1}{J_{c}}=\left(\frac{\ln K_{\lg s}}{3 \pi}\right)^{1 / 2} \frac{27}{8} \frac{\Delta S_{m}\left(\theta_{2 \lg s}-\varepsilon_{\lg s}\right)^{3}}{N_{A} k_{B}\left(1+\varepsilon_{\lg s}\right)^{3} \ln K_{\lg s}} \\
\tau_{0}=\frac{\pi N_{A} k_{B}(3 \pi)^{1 / 2}}{6} \frac{N_{A}}{V_{m}} \frac{\left(1+\theta_{2 \lg s}\right)\left(\ln K_{\lg s}\right)^{1 / 2}}{\Delta S_{m} A_{g}}
\end{gathered}
$$

where $\Delta S_{\mathrm{m}}$ is the fusion entropy per mole, $\mathrm{N}_{\mathrm{A}}$ the Avogadro number, $\theta_{2 \operatorname{lgs}}$ defined by (3), $\mathrm{N}_{\mathrm{A}} \mathrm{k}_{\mathrm{B}}=8.32$ Joule. The temperature $\mathrm{T}_{2 \mathrm{lgs}}\left(\right.$ or $\theta_{2 \operatorname{lgs}}$ ) is a constant of the material and a unique function of 
the energy saving $\varepsilon_{\operatorname{lgs}}$ in (3). It does not strictly depend on viscosity. Nevertheless, the viscosity has a strong influence on the occurrence of the maximum nucleation rate temperature because the critical energy barrier $\Delta \mathrm{G}^{*}{ }_{2 \mathrm{gg}} / \mathrm{k}_{\mathrm{B}} \mathrm{T}$ is proportional to $\ln \mathrm{K}_{\mathrm{lgs}}$ and the numerical coefficient of $\ln \mathrm{K}_{\operatorname{lgs}}$ in $\Delta \mathrm{G}^{*}{ }_{2 \mathrm{lgs}} / \mathrm{k}_{\mathrm{B}} \mathrm{T}$ is equal to about 1 in a broad window of temperatures above $\mathrm{T}_{\mathrm{g}}{ }_{\mathrm{g}}$. The critical energy barrier $\Delta \mathrm{G}^{*}{ }_{2 \lg s} / \mathrm{k}_{\mathrm{B}} \mathrm{T}$ is nearly the same at $\mathrm{T}^{*}{ }_{\mathrm{g}}$ for all glass-forming melts and $\ln \mathrm{K}_{\operatorname{lgs}}$ decreases with the increase in viscosity. The nucleation rate is at a maximum when $\ln K_{\operatorname{lgs}}$ becomes exactly equal to $\Delta \mathrm{G}^{*}{ }_{2 \mathrm{lg}} / \mathrm{k}_{\mathrm{B}} \mathrm{T}_{\mathrm{g}}$. This event occurs at $\mathrm{T}_{\mathrm{g}}\left(\right.$ or $\theta_{\mathrm{g}}$ ) $=\mathrm{T}_{2 \mathrm{lgs}}\left(\right.$ or $\left.\theta_{2 \mathrm{ls}}\right)$ for similar viscosity values because $\tau_{0}$, and the relaxation time $\tau_{g}^{n s}$ are nearly the same in all glass-forming melts at $\mathrm{T}_{\mathrm{g}}$.

The relaxation time $\tau_{g}^{n s}$ is generally of the order of $100 \mathrm{~s}$ at $\mathrm{T}_{\mathrm{g}}$. A value $\tau_{0}=1.4 \times 10^{-14} \mathrm{~s}$ is deduced with $\mathrm{B} /\left(\mathrm{T}_{\mathrm{g}}-\mathrm{T}_{0 \mathrm{~g}}\right)=36.5$ and $\tau_{0}=3.14 \times 10^{-15} \mathrm{~s}$ with $\mathrm{B} /\left(\mathrm{T}_{\mathrm{g}}-\mathrm{T}_{0 \mathrm{~g}}\right)=38$ in all glasses $[3,9,27]$. Equation (17) giving $\tau_{0}$ is used to determine $\ln \mathrm{A}_{\mathrm{g}}$ only, depending on $\left\{\ln \left(1+\theta_{2 \operatorname{lgs}}\right]-\ln \left[\mathrm{V}_{\mathrm{m}} \times \Delta \mathrm{S}_{\mathrm{m}}\right]\right.$.

With $\tau_{0}=1.4 \times 10^{-14} \mathrm{~s}$, the $\ln \mathrm{A}_{\mathrm{g}}$ is equal to 100.7 in $\mathrm{N}^{\circ} 6 \mathrm{Pd}_{43} \mathrm{Ni}_{10} \mathrm{Cu}_{27} \mathrm{P}_{20}\left(\mathrm{~V}_{\mathrm{m}}=8 \times 10^{-6} \mathrm{~m}^{3}\right.$, $\left.\Delta \mathrm{S}_{\mathrm{m}}=8.74 \mathrm{~J} / \mathrm{K}, \theta_{2 \operatorname{lgs}}=-0.271\right)$ and to $96.4 \mathrm{in} \mathrm{N}^{\circ} 20$ Glycerol $\left(\mathrm{V}_{\mathrm{m}}=73.07 \times 10^{-6} \mathrm{~m} 3, \Delta \mathrm{S}_{\mathrm{m}}=62.42 \mathrm{~J} / \mathrm{K}\right.$, $\theta_{2 \operatorname{lgs}}=-0.352$ ).

With $\tau_{0}=3.14 \times 10^{-15} \mathrm{~s}$, the $\ln \mathrm{A}_{\mathrm{g}}$ is respectively equal to 102.2 and 97.9 for the same liquids with an increase of the product $\mathrm{V}_{\mathrm{m}} \times \Delta \mathrm{S}_{\mathrm{m}}$ by a factor 66 .

With $\tau_{0}=1.4 \times 10^{-14} \mathrm{~s}$, the average value of $\ln \mathrm{A}_{\mathrm{g}}$ is $98.5 \pm 2$ and with $\tau_{0}=3.14 \times 10^{-15} \mathrm{~s}$, $\ln A_{g}=100 \pm 2$. The $\ln K_{\operatorname{lgs}}$ and the thermally-activated energy barrier $\Delta \mathrm{G}^{*}{ }_{2 \operatorname{lgg}} / \mathrm{k}_{\mathrm{B}} \mathrm{T}_{2}$ are always equal to $62 \pm 2$ in all glass-forming melts at $\mathrm{T}=\mathrm{T}_{\mathrm{g}}$.

Equation (15) shows that the assumption of a value of $\tau_{0}$ being the same in all melts can be replaced by a nearly-constant value of $\mathrm{A}_{\mathrm{g}} ; \ln \mathrm{A}_{\mathrm{g}}$ is about $15 \%$ larger than the one found for crystal nucleation from surviving crystals in several glass-forming melts at higher temperatures [14]. Then, the time lag of a transient nucleation to produce a crystal nuclei distribution, built from surviving crystals and ready for steady-state nucleation, is about $10^{6}$ times larger than the time lag $\tau_{g}^{n s}$ required for a homogeneously-nucleated cluster distribution formation. The steady-state nucleation time $\mathrm{t}_{\mathrm{sn}}$ is, in addition, equal to $10^{9} \mathrm{~s}$ for $\mathrm{v}=10^{-9} \mathrm{~m}^{3}$. A nucleus distribution with cluster size close to the critical value is created just near $\mathrm{T}_{\mathrm{g}}$ when the relaxation time is minimum. In Turnbull and Fisher's model, $\ln K_{1 s}$ is nearly equal to $\ln \left(\mathrm{N}_{\mathrm{A}} \mathrm{k}_{\mathrm{B}} \mathrm{T}^{*} \mathrm{~g} / \mathrm{V}_{\mathrm{m}} \mathrm{h}\right)-\Delta \mathrm{f} * / \mathrm{k}_{\mathrm{B}} \mathrm{T}_{\mathrm{g}}{ }_{\mathrm{g}}$ where $\mathrm{h}$ is Planck's constant and $\Delta \mathrm{f} * / \mathrm{k}_{\mathrm{B}} \mathrm{T}^{*}{ }_{\mathrm{g}}$ is a thermally-activated energy barrier for atom diffusion from the melt to the homogeneously-nucleated cluster which is smaller than the one from the melt to a surviving crystal [65]. This weakening could be due to formation of clusters containing many vacancies on their various sub-lattices during homogeneous nucleation. Surviving crystals are expected to be well-crystallized because they are part of previously-crystallized materials. They did not melt above $\mathrm{T}_{\mathrm{m}}$ and they are very stable with their fusion heat equal to the bulk one [21-23].

\subsection{The Thermodynamic Vitreous Transition $T^{*}{ }_{g}$ at the Disappearance Temperature of the} Fully-Relaxed Enthalpy

A relaxed enthalpy is measured by DSC, after quenching the undercooled liquid to much lower temperatures than $T_{g}$ and annealing it at a temperature $T_{a}$ smaller than $T_{g}$, during the relaxation time necessary to obtain its maximum value $\mathrm{H}_{\mathrm{r}}$. The structural relaxation is viewed as a transformation of 
the quenched undercooled liquid state in a fully-frozen state. This exothermic heat varies linearly with $\left(\mathrm{T}_{\mathrm{g}}^{*}-\mathrm{T}_{\mathrm{a}}\right.$ ) as shown in Figures 2 and 3. The fully-relaxed enthalpies $\mathrm{H}_{\mathrm{r}}$ of $\mathrm{As}_{2} \mathrm{Se}_{3}$ and $\mathrm{Zr}_{58.5} \mathrm{Cu}_{15.6} \mathrm{Ni}_{12.8} \mathrm{Al}_{10.3} \mathrm{Nb}_{2.8}$ (vit106a) are plotted in Figure 2 using values of $\mathrm{T}_{\mathrm{g}}$ equal to 462 and $690 \mathrm{~K}$ instead of $\mathrm{T}_{\mathrm{g}}=450$ and $673 \mathrm{~K}$ respectively $[54,66,67]$. The calculated temperatures $\mathrm{T}_{0 \mathrm{~g}}$ are respectively $293 \mathrm{~K}$ and $437 \mathrm{~K}$ as compared to $\mathrm{T}_{02}=335$ and $437 \mathrm{~K}$. The vitreous transition $\mathrm{T}_{\mathrm{g}}$ of $\mathrm{As}_{2} \mathrm{Se}_{3}$ exactly corresponds to the mid-point of the reversible specific heat jump [67]. In Figure 3 we describe the relaxed enthalpy variation of propylene glycol and glycerol extracted from two different publications with $\mathrm{T}_{\mathrm{g}}=171$ and $189.8 \mathrm{~K}$ instead of $\mathrm{T}_{\mathrm{g}}=167$ and $190 \mathrm{~K}$ respectively $[68,69]$. The calculated temperatures $\mathrm{T}_{0 \mathrm{~g}}$ are respectively $112 \mathrm{~K}$ and $121 \mathrm{~K}$ as compared to $\mathrm{T}_{02}=117$ and $128 \mathrm{~K}$.

The specific heat excess of the undercooled melt $\Delta \mathrm{C}_{\mathrm{pgl}}$ can be directly calculated from $\mathrm{dH}_{\mathrm{r}} / \mathrm{dT}_{\mathrm{a}}=\Delta \mathrm{C}_{\mathrm{pgl}}$ because $\mathrm{H}_{\mathrm{r}}$ is a linear function of $\mathrm{T}_{\mathrm{a}}$ and $H_{r}=\int_{T_{a}}^{T_{g}^{*}} \Delta C_{p g l} d T$. The following calculated values of $\Delta \mathrm{C}_{\mathrm{pgl}}$ are in good agreement with the specific heat difference $\Delta \mathrm{C}_{\mathrm{pls}}$ between solid and liquid; for propylene glycol, $\Delta \mathrm{C}_{\mathrm{pgl}}=52.3$ and $\Delta \mathrm{C}_{\mathrm{pls}}=67.3 \mathrm{~J} / \mathrm{mole} / \mathrm{K}[68,69]$; for glycerol, $\Delta \mathrm{C}_{\mathrm{pgl}}=69.9$ and $\Delta \mathrm{C}_{\mathrm{pls}} \cong 79.4 \mathrm{~J} / \mathrm{mole} / \mathrm{K}[32,68,69]$; for vit106a, $\Delta \mathrm{C}_{\mathrm{pgl}}=13.5$ and $\Delta \mathrm{C}_{\mathrm{pls}} \cong 15.5 \mathrm{~J} / \mathrm{mole} / \mathrm{K}$ [54]; for $\mathrm{As}_{2} \mathrm{Se}_{3}, \Delta \mathrm{C}_{\mathrm{pgl}}=67 \mathrm{~J} / \mathrm{mole} / \mathrm{K}$ from the relaxed enthalpy and $67 \mathrm{~J} / \mathrm{mole} / \mathrm{K}$ from the reversible specific heat [67]. The specific heat jump $\Delta \mathrm{C}_{\mathrm{pls}}$ is a little too large at $\mathrm{T}_{\mathrm{g}}$ when it is measured at a too low heating rate because it still contains an endothermic contribution except when stepscan techniques are used [13].

Figure 2. The saturated value of the relaxed enthalpy $\mathrm{H}_{\mathrm{r}}$ is plotted versus $\left(\mathrm{T}_{\mathrm{g}}{ }_{\mathrm{g}}-\mathrm{T}_{\mathrm{a}}\right), \mathrm{T}^{*} \mathrm{~g}$ being the thermodynamic vitreous transition and $\mathrm{T}_{\mathrm{a}}$ the annealing temperature; for $\mathrm{N}^{\circ} 35$ vit $106 \mathrm{a}$ $\left(\mathrm{Zr}_{58.5} \mathrm{Cu}_{15.6} \mathrm{Ni}_{12.8} \mathrm{Al}_{10.3} \mathrm{Nb}_{2.8}\right), \mathrm{T}_{\mathrm{g}}^{*}=690 \mathrm{~K}$ and the slope of the straight line $\Delta \mathrm{C}_{\mathrm{pgl}}=13.5 \mathrm{~J} / \mathrm{g}$.atom and for $\mathrm{N}^{\circ} 10 \quad \mathrm{As}_{2} \mathrm{Se}_{3}, \mathrm{~T}_{\mathrm{g}}^{*}=462 \mathrm{~K}$ and $\Delta \mathrm{C}_{\mathrm{pgl}}=13.5 \mathrm{~J} / \mathrm{g}$.atom [54,66,67]. The corresponding values of $\mathrm{T}_{0 \mathrm{~g}}$ calculated from $\mathrm{T}_{\mathrm{g}}^{*}$ are $443 \mathrm{~K}$ and $293 \mathrm{~K}$. The deviation from the straight line is due to the approach of the Kauzmann temperature of $\mathrm{As}_{2} \mathrm{Se}_{3}$ [67].

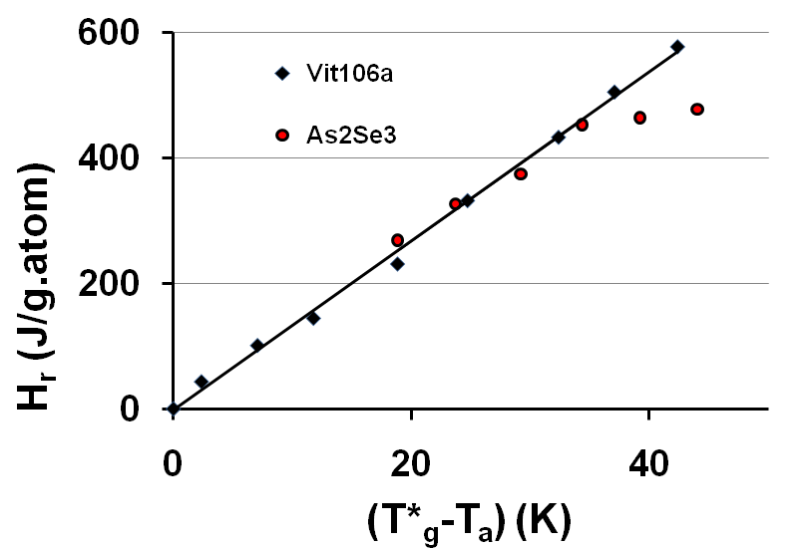


Figure 3. The saturated value of the relaxed enthalpy $H_{r}$ is plotted versus $\left(T^{*}{ }_{g}-T_{a}\right), T^{*} g$ being the thermodynamic vitreous transition and $\mathrm{T}_{\mathrm{a}}$ the annealing temperature; for $\mathrm{N}^{\circ} 20$ glycerol, $\mathrm{T}_{\mathrm{g}}^{*}=189.8 \mathrm{~K}$ and the slope of the straight line $\Delta \mathrm{C}_{\mathrm{pgl}}=4.99 \mathrm{~J} / \mathrm{g}$.atom and for $\mathrm{N}^{\circ} 2$ propylene glycol $\mathrm{T}_{\mathrm{g}}^{*}=171 \mathrm{~K}$ and $\Delta \mathrm{C}_{\mathrm{pgl}}=4.02 \mathrm{~J} / \mathrm{g}$.atom. The corresponding values of $\mathrm{T}_{0 \mathrm{~g}}$ calculated from $\mathrm{T}^{*} \mathrm{~g}$ are 121 and $112 \mathrm{~K}$ respectively. The largest values of $\mathrm{H}_{\mathrm{r}}$ are due to [68] and the smallest ones to [69].

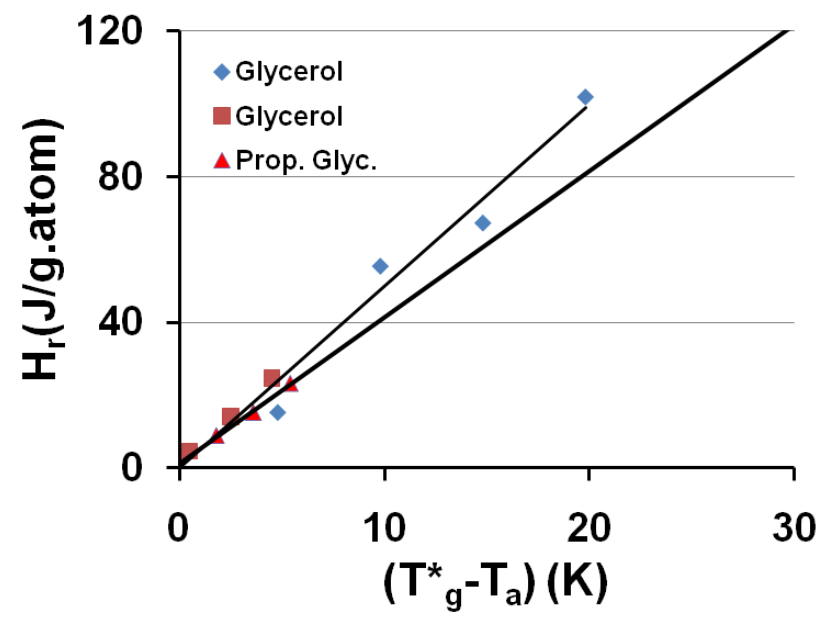

The specific heat excess of an undercooled melt tends to zero at the Kauzmann temperature as shown by the fact that the derivative $\mathrm{d} \Delta \mathrm{H}_{\mathrm{r}} / \mathrm{dT}$ of $\mathrm{As}_{2} \mathrm{Se}_{3}$ tends to zero at this temperature as reproduced in Figure 2 [66,67]; the Kauzmann temperature $\mathrm{T}_{\mathrm{k}}$ is an actual temperature of undercooled melts instead of a virtual one [67].

\subsection{The Crystal Homogeneous Nucleation Temperature at $T^{*}{ }_{g}$}

The vitreous transition $\mathrm{T}_{\mathrm{g}}$ ( or $\theta_{\mathrm{g}}$ ) is viewed as occurring at the crystal steady-state nucleation maximum-rate temperature $\mathrm{T}_{2 \mathrm{gg}}$ (or $\theta_{2 \mathrm{lg}}$ ). In this case, the glass transition being a material constant has to obey (6). The energy saving approximate coefficients $\varepsilon_{\operatorname{lgs} 0}$ in Table 1 are given by (18) using $\mathrm{T}_{\mathrm{g}}$ which is not known instead of $\mathrm{T}^{*} \mathrm{~g}$ :

$$
\varepsilon_{\lg s 0}=1.5 \times \theta_{g}+2
$$

The corresponding temperatures $\mathrm{T}_{0 \mathrm{~g}}=\mathrm{T}_{0 \mathrm{lgs}}\left(\right.$ or $\theta_{0 \mathrm{~g}}=\theta_{0 \mathrm{lgs}}$ ) listed in Table 1 , are calculated from $\varepsilon_{\operatorname{lgs} 0}$ determined by $(18)$ and $(7,8)$. The calculated temperature $\mathrm{T}_{0 \mathrm{~g}}$ of the free volume disappearance is plotted as a function of the VFT temperature $\mathrm{T}_{02}$ in Figure 4 . The average of $\mathrm{T}_{0 \mathrm{~g}}$ is $3.6 \%$ larger than that of $\mathrm{T}_{02}$. These quantities are nearly equal if we consider that $\mathrm{T}_{\mathrm{g}}$ is an out-of-equilibrium temperature which is not exactly equal to the thermodynamic transition $\mathrm{T}^{*} \mathrm{~g}$. The model works and is able to predict the VFT temperature of fragile glass-forming melts when $\mathrm{T}^{*_{\mathrm{g}}}$ is known. 
Figure 4. The calculated values of the free-volume disappearance temperature $\mathrm{T}_{0 \mathrm{~g}}$ of fragile glass-forming melts are plotted versus the VFT temperatures $\mathrm{T}_{02}$ determined by measurements in the vicinity of $\mathrm{T}_{\mathrm{g}} ; \mathrm{T}_{0 \mathrm{~g}} \cong 1.036 \mathrm{~T}_{02}$.

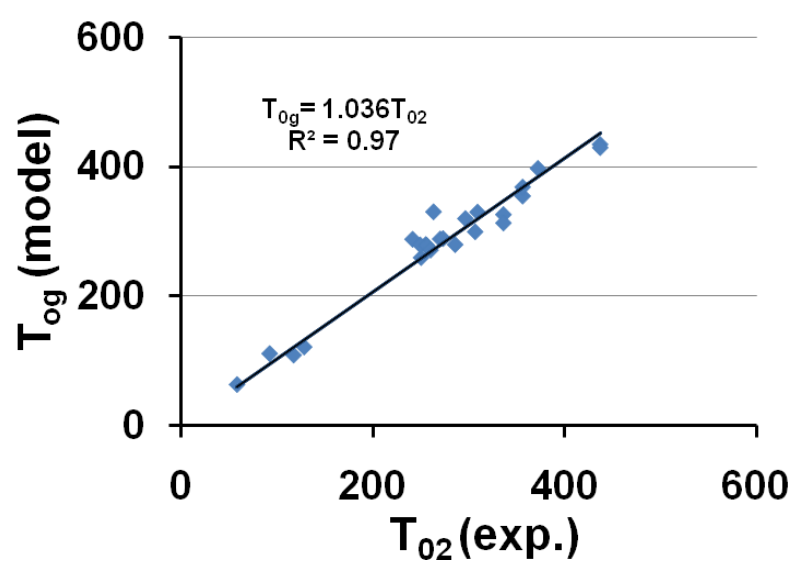

The energy saving coefficients $\varepsilon_{\operatorname{lgs} 0}$ and $\varepsilon_{\mathrm{ls} 0}$ are not equal and correspond to the two reduced temperatures $\theta_{0 \mathrm{~g}}$ and $\theta_{0 \mathrm{~m}}$ given by (6). The coefficient $\varepsilon_{\mathrm{ls} 0}$ is calculated using $\mathrm{T}_{0 \mathrm{~m}}$ and $\mathrm{T}_{\mathrm{g}}$ of $\mathrm{N}^{\circ} 29$ vit105 $\left(\mathrm{Zr}_{52.5} \mathrm{Cu}_{17.9} \mathrm{Ni}_{14.6} \mathrm{Al}_{10} \mathrm{Ti}_{5}\right)$ because the scaling law $\mathrm{T}_{0 \mathrm{~m}}=0.77 \times \mathrm{T}_{\mathrm{g}}[7,64]$ is obeyed by this material. $\Delta \varepsilon\left(\theta_{\mathrm{g}}\right)=\left(\varepsilon_{\mathrm{ls} 0}-\varepsilon_{\mathrm{lg} 0}\right)$ is equal to 0 for $\theta_{\mathrm{g}}=0$ and 0.19 for $\theta_{\mathrm{g}}=-0.381$. These two particular values are used to determine a possible scaling law followed by $\Delta \varepsilon$. The crystal nucleation maximum-rate temperature $\theta_{2 \mathrm{ls}}$ is given by $(7,8)$ as a function of $\varepsilon_{\mathrm{ls} 0}$; then, $\varepsilon_{\mathrm{ls} 0}$ and $\varepsilon_{\mathrm{ls} 0}-\varepsilon_{\mathrm{lg} 0}=\Delta \varepsilon$ have to be linear functions of $\theta_{\mathrm{g}}$ given by (11):

$$
\begin{gathered}
\varepsilon_{l s 0}=\theta_{g}+2 \\
\varepsilon_{l s 0}-\varepsilon_{\lg 0}=\Delta \varepsilon=-0.5 \times \theta_{g}
\end{gathered}
$$

The two energy saving coefficients $\varepsilon_{\mathrm{ls} 0}$ and $\varepsilon_{\mathrm{lg} 0}$ given in Table 1 are plotted as a function of $\theta_{\mathrm{g}}$ in Figure 5. Equations (7) and (8) are used to predict the temperatures $\mathrm{T}_{0 \mathrm{~g}}$ and $\mathrm{T}_{0 \mathrm{~m}}$ also given in Table 1 and plotted as a function of $\mathrm{T}_{\mathrm{g}}$ in Figure 6 . These values are the free-volume disappearance temperatures of glass-forming melts having a thermodynamic glass transition occurring at $\mathrm{T}_{\mathrm{g}}=\mathrm{T}_{\mathrm{g}}$.

Figure 5. The energy saving coefficients $\varepsilon_{\operatorname{ls} 0}$ and $\varepsilon_{\lg 0}$ are calculated respectively using the scaling laws $(18)$ and $(19,20)$ and are plotted versus $\theta_{\mathrm{g}}=\left(\mathrm{T}_{\mathrm{g}}-\mathrm{T}_{\mathrm{m}}\right) / \mathrm{T}_{\mathrm{m}}$.

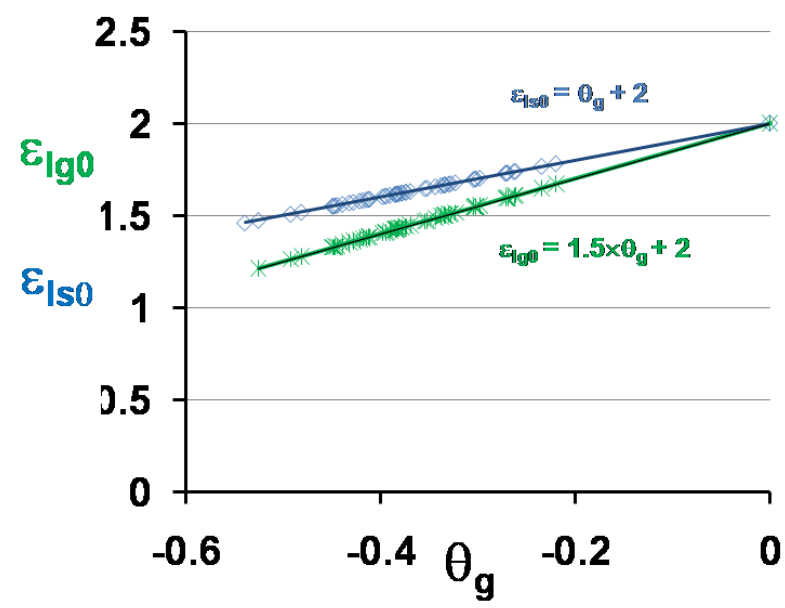


Figure 6. The calculated values of the free-volume disappearance temperatures $\mathrm{T}_{0 \mathrm{~m}}$ and $\mathrm{T}_{0 \mathrm{~g}}$ are plotted versus $\mathrm{T}_{\mathrm{g}}$; they are equal to the VFT temperatures $\mathrm{T}_{01}$ and $\mathrm{T}_{02}$ represented in Figure $1 . \mathrm{T}_{0 \mathrm{~m}}=0.77 \mathrm{~T}_{\mathrm{g}}$ and $\mathrm{T}_{0 \mathrm{~g}}=0.65 \mathrm{~T}_{\mathrm{g}}$.

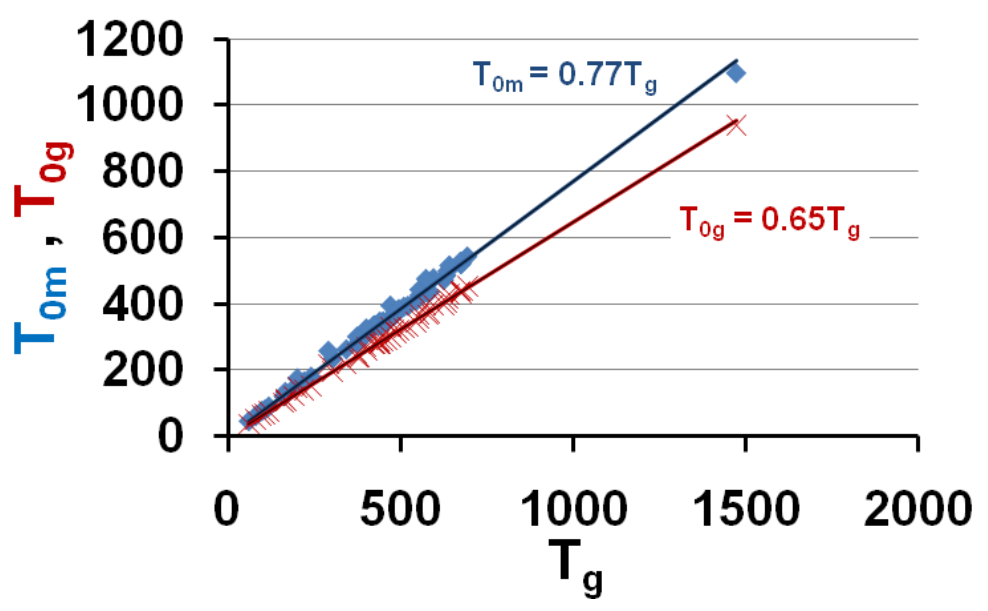

These predictions are in very good agreement with experiments when we compare Figure 6 to Figures 1 and 4. Then, the vitreous transition corresponds to a crystal homogeneous nucleation temperature. A distribution of homogeneously-nucleated clusters is created when the temperature decreases down to $\mathrm{T}^{*} \mathrm{~g}$. The scaling laws (18) and (19) are obeyed and reflect intrinsic properties of glass-forming melts. The two VFT temperatures corresponding to two free-volume disappearance temperatures follow intrinsic scaling laws related to a change of the energy saving in all melts. These predictions can be more precise as shown in Figures 7 and 8. In fact, the ratios $T_{o m} / T_{g}$ and $T_{0 g} / T_{g}$ are weakly varying with the glass transition; the proportionality coefficients 0.77 and 0.65 are mean values for a lot of glasses and polymers having $\theta_{\mathrm{g}}$ values larger than -0.45 and smaller than -0.2 . The ratio $\mathrm{T}_{0 \mathrm{~m}} / \mathrm{T}_{0 \mathrm{~g}}$ is nearly constant in the same interval of $\theta_{\mathrm{g}}$ values as shown in Figure 6; it tends to 1 when $\theta_{\mathrm{g}}$ tends to 0 and $-2 / 3$.

Figure 7. The ratios $\mathrm{T}_{\mathrm{og}} / \mathrm{T}_{\mathrm{g}}$ and $\mathrm{T}_{0 \mathrm{~m}} / \mathrm{T}_{\mathrm{g}}$ of the free-volume disappearance temperatures to the glass transition temperature $T_{g}$ are plotted versus $\theta_{g}=\left(T_{g}-T_{m}\right) / T_{m}$.

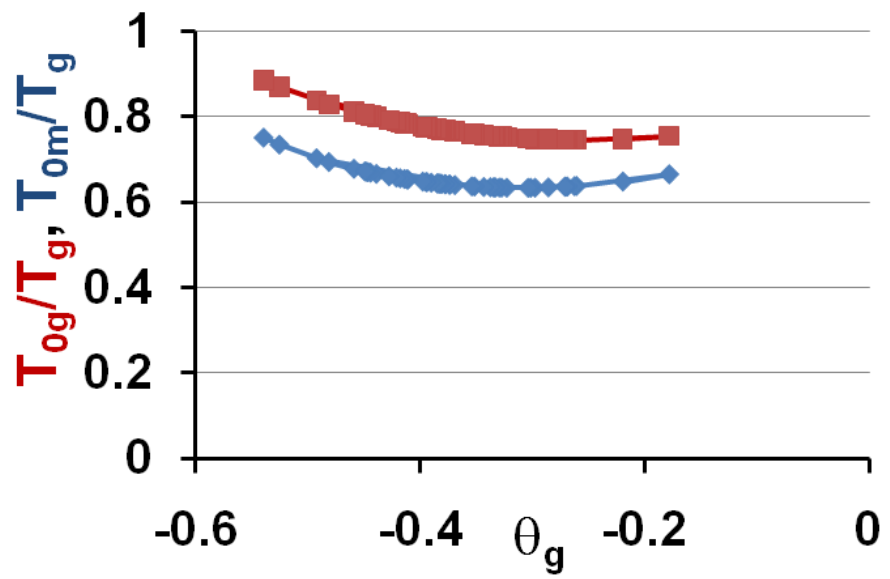


Figure 8. The ratios of the free-volume disappearance temperatures $T_{o m} / T_{o g}$ are plotted versus $\theta_{\mathrm{g}}=\left(\mathrm{T}_{\mathrm{g}}-\mathrm{T}_{\mathrm{m}}\right) / \mathrm{T}_{\mathrm{m}}$.

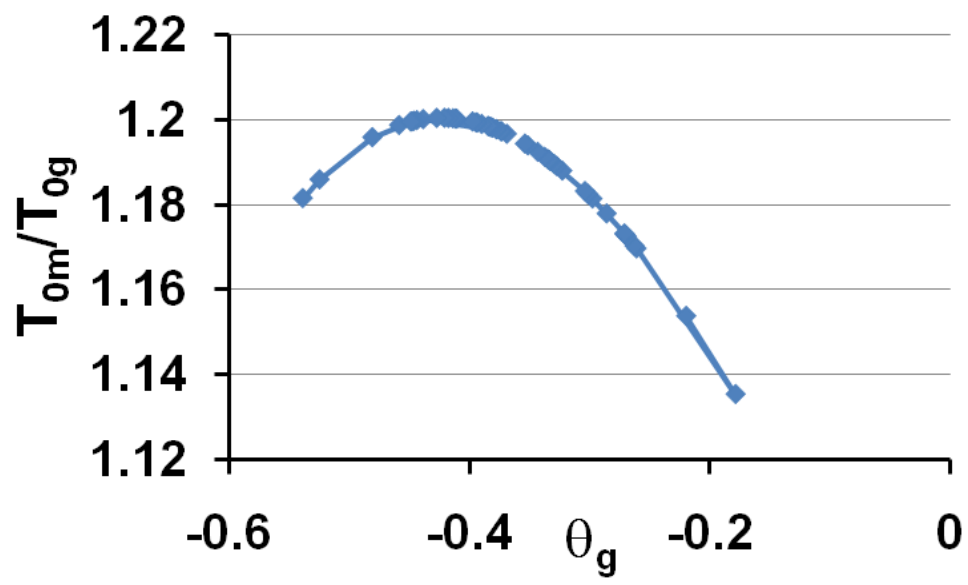

\subsection{Volume Energy Saving Associated with Nascent Crystals in Non-Metallic Glass-Forming Melts}

Volume energy saving associated with homogeneously-nucleated crystal formation also exists in non-metallic liquids. It could be due to an electrostatic interaction between a screen of ionic charges present in the melt and charges carried by homogeneously-nucleated crystals containing unoccupied ionic sites. Homogeneous nucleation gives rise, in a first step, to ultra-fine crystals among density fluctuations. Ions of opposite charges could be randomly distributed inside their own sub-lattices in a crystal. The mean charge carried by such crystals would be proportional to the square root of their atom number $\mathrm{n}$. Counter-ions of opposite charge would screen the grain charge and induce an attractive interaction proportional to the square of the grain charge and then to the atom number $n$. Neel already made a similar assumption to explain the superparamagnetic (ferrimagnetic) properties of antiferromagnetic ultra-fine grains. The superparamagnetic Curie constant of ultra-fine grains is equal to the Curie constant of $\mathrm{n}$ paramagnetic atoms because the magnetic moments carried by different ions are randomly distributed in their own sub-lattices and the grain uncompensated magnetic moment is proportional to $\mathrm{n}^{1 / 2}[70]$.

The presence of volume energy saving in nonmetallic glass-forming melts is also due to a more general phenomenon associated with the formation of noncritical clusters in melts containing $\mathrm{n}$ atoms. The chemical potential of a small cluster is expected to differ from the bulk value. A new contribution $-\left(p-p_{0}\right) V_{m}$ ought to be added to the classical Gibbs free energy change. It depends on the Laplace pressure $\mathrm{p}$ applied to the cluster when a cluster is formed, $\mathrm{p}_{0}$ being the classical pressure of the melt on the solid particle, regardless of its size. This complementary contribution is not involved in the classical Gibbs free energy change because the pressure $p$ is not homogeneous in the melt [71]. The Laplace pressure $\mathrm{p}$ increases with a decreasing atom number $\mathrm{n}$. In addition, the energy saving is quantified when the critical cluster radius and the number of transferred electrons are very small in metallic glass-forming melts [14-15]. The temperature dependence of $\varepsilon_{\mathrm{ls}}$ given by (1) is a general law for nascent clusters in all melts. 


\subsection{Thermodynamic Origin of Relaxed Enthalpy and of Out-of-Equilibrium Nucleation}

\section{Temperatures $T_{g}$}

Enthalpy is relaxed at the annealing temperature $\mathrm{T}_{\mathrm{a}}<\mathrm{T}^{*} \mathrm{~g}$ applied after quenching the undercooled melt down to a much lower temperature. The fully-relaxed enthalpy is equal to $H_{r}=\Delta C_{p l g}\left(T^{*}\right) \times\left[T^{*}-T_{a}\right]$ for $\mathrm{T}_{\mathrm{k}}<\mathrm{T}_{\mathrm{a}}<\mathrm{T}^{*} \mathrm{~g}$ instead of being related to the enthalpy excess stored by an undercooled melt quenched from $T_{a}$ down to the Kauzmann temperature $T_{k}$ and to the entropy available below $T_{a}$. So this relaxed enthalpy correlated to the thermodynamic transition.

The annealing temperature $T_{a}$ is an out-of-equilibrium homogeneous nucleation temperature of a fragile glass-forming melt and a solution of (6) corresponding, for the same value of $\theta_{0 \text { lgs }}$, to an energy saving coefficient of nascent crystals at $\mathrm{T}_{\mathrm{m}}$ being a little larger than the equilibrium value at a

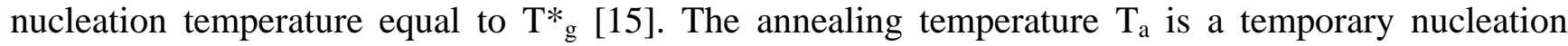
temperature during the time lag of the transient nucleation. The undercooled melt progressively relaxes enthalpy and entropy excesses stored between $\mathrm{T}_{\mathrm{a}}$ and $\mathrm{T}_{\mathrm{g}}$ towards their equilibrium values at $\mathrm{T}_{\mathrm{g}}$. The existence of this relaxed enthalpy is a strong argument in favor of a thermodynamic equilibrium at $\mathrm{T}^{*} \mathrm{~g}$. The time-dependent vitreous transition $\mathrm{T}_{\mathrm{g}}$ is due to this endothermic heat appearing at a temperature varying with the heating rate in a DSC run. A nucleation temperature $T_{2 l s}=T_{g}$ could also exist above $\mathrm{T}^{*} \mathrm{~g}$ when high heating rates are used because the homogeneous nucleation temperature $\mathrm{T}_{2 \mathrm{ls}}$ only depends on the energy saving coefficient $\varepsilon_{\lg 50}$ for a well-defined ideal glass transition temperature $\mathrm{T}_{0 \mathrm{~g}}$ (or $\theta_{0 \mathrm{~g}}$ ) as shown by (6) and Figure 9.

Figure 9. The out-of-equilibrium homogeneous nucleation temperatures $T_{21 s}=T_{g}$ equal to homogeneous nucleation temperatures depend on energy saving coefficients $\varepsilon_{\operatorname{lgs} 0}$ through (6). The equilibrium transition of vit $106 \mathrm{a}\left(\mathrm{Zr}_{58.5} \mathrm{Cu}_{15.6} \mathrm{Ni}_{12.8} \mathrm{Al}_{10.3} \mathrm{Nb}_{2.8}\right)$ at $\mathrm{T}_{\mathrm{g}}=690 \mathrm{~K}$ has been previously determined as shown in Figure 2 . The temperature $\mathrm{T}_{0 \mathrm{~g}}=437 \mathrm{~K}$ is equal to $\mathrm{T}_{02}$.

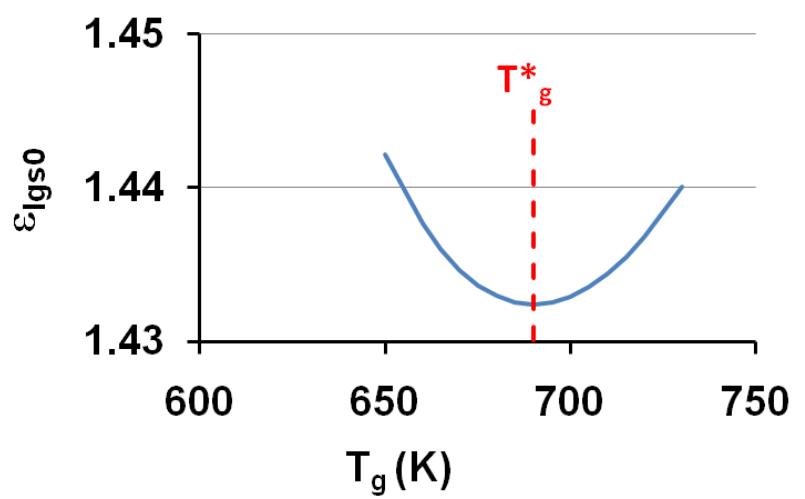

A spin-glass transition is also characterized in zero field by the presence at once of a time-dependent susceptibility cusp temperature, a phase transition temperature and, in the magnetic field, by two lines of transition $\mathrm{H}_{\mathrm{c}}(\mathrm{T})$ and $\mathrm{H}_{\mathrm{m}}(\mathrm{T})$ [72]. The phase diagram $(\mathrm{H}, \mathrm{T})$ of $\mathrm{Cu}-\mathrm{Mn}$ has been investigated by measuring magnetocaloric effects showing the importance of the entropy $\mathrm{S}(\mathrm{T}, \mathrm{H})$ in understanding the physics of spin glass transition. $\mathrm{The}_{\mathrm{c}}(\mathrm{T})$ is the boundary line spin-glass/non-Curie paramagnet. The $\mathrm{H}_{\mathrm{m}}(\mathrm{T})$ is a cross-over line Curie/Non-Curie paramagnet corresponding to an irreversibility line and to a freezing of rigid clusters of spins [72-74]. The spin-glass phase transition 
can be separated from the irreversibility line when the magnetic field frequency increases. The existence of this type of phenomenon in glasses remains an open question because the reversible specific heat jump always occurs in $\mathrm{As}_{2} \mathrm{Se}_{3}$ at the same vitreous transition regardless of the heating and cooling rates [67].

\section{Summary and Complementary Information on the Two Crystal Nucleation Temperatures}

New equations governing the crystal nucleation, reflecting the energy saving associated with Fermi energies equalization of nascent crystals and melt, have been used and applied to all glass-forming melts. The vitreous transition is characterized by freezing at a crystal homogeneous nucleation temperature only determined by thermodynamics considerations. We have shown, for the first time, that an energy scale governs the vitreous transition. This material constant does not strictly depend on the viscosity, even if the viscosity is high and nearly the same at $\mathrm{T}_{\mathrm{g}}$, because the energy barrier for crystal growth nucleation $\Delta \mathrm{G}^{*}{ }_{21 \mathrm{~s}}$ divided by $\mathrm{k}_{\mathrm{B}} \mathrm{T}_{\mathrm{g}}$ is nearly the same in all glass-forming melts. The energy barrier $\Delta \mathrm{f}^{*}$ to transfer an atom from the melt to a nascent crystal divided by $\mathrm{k}_{\mathrm{B}} \mathrm{T}_{\mathrm{g}}$ is also nearly the same and is a little smaller than the one from transport across the melt-crystal interfaces at the first crystallization temperature which is induced by surviving intrinsic crystals.

These findings are in agreement with published works having shown that the reversible specific heat jump at $\mathrm{T}_{\mathrm{g}}^{*}$ does not depend on time and on sample thermal history. In addition, the relaxed enthalpy disappears at the thermodynamic transition $\mathrm{T}^{*} \mathrm{~g}$ and its maximum value obtained at each annealing temperature $\mathrm{T}_{\mathrm{a}}$ after quenching the undercooled liquid to lower temperatures, is given by $H_{r}=\int_{T_{a}}^{T_{g}^{*}} \Delta C_{p g l} d T, \Delta \mathrm{C}_{\mathrm{pgl}}$ being the specific heat jump at $\mathrm{T}_{\mathrm{g}}$. The apparent specific heat jump at $\mathrm{T}_{\mathrm{g}}$ calculated from the heat flux measurement is equal to the reversible one. The specific heat jump deduced from heat flux measurement occurs at a temperature $\mathrm{T}_{\mathrm{g}}$ depending on the heating rate. There is no visible anomaly at $\mathrm{T}^{*}$ in a DSC run. This phenomenon is schematized in Figure 10. The glass transition temperatures $\mathrm{T}_{\mathrm{g}}$ determined by DSC correspond to out-of-equilibrium crystal homogeneous nucleation temperatures and to out-of-equilibrium values of the energy saving coefficient $\varepsilon_{\lg 0}$.

Figure 10. The reversible thermodynamic vitreous transition occurs at $T=T^{*}$; the specific heat decreases along $\mathrm{AB}$; the specific heat of the vitreous fully-frozen state along $\mathrm{BD}$ is equal to the crystallized state. The undercooled melt is quenched at low temperatures and annealed at the temperature $\mathrm{T}_{\mathrm{a}}$. The transformation from $\mathrm{C}$ to $\mathrm{D}$ relaxes an enthalpy equal to the surface ABDC when the time-lag necessary for cluster formation has evolved.

Specific heat versus Temperature

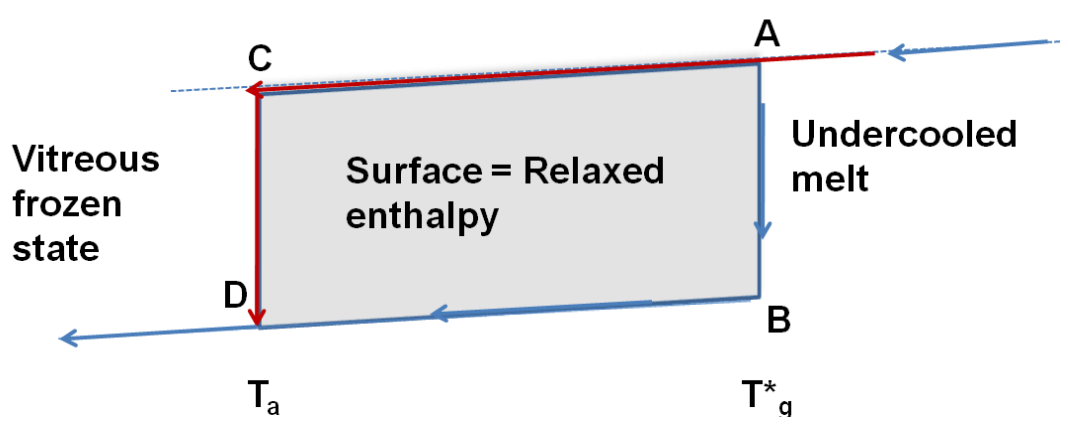


The thermodynamic transition $\mathrm{T}^{*_{\mathrm{g}}}$ is a linear function of the energy saving divided by the fusion heat associated, in a nascent crystal formation, with the equalization of Fermi energy or chemical potential of nascent crystals and glass-forming melts. It is possible to predict, only using $\mathrm{T}_{\mathrm{g}}$ and the melting temperature $T_{m}$, a free-volume disappearance temperature equal to the VFT temperature of fragile-glass-forming melts deduced from viscosity and relaxation time measurements above and near $\mathrm{T}^{*} \mathrm{~g}$. There are two crystal homogeneous nucleation temperatures which follow scaling laws linearly dependent on two energy saving coefficients $\varepsilon_{\mathrm{ls} 0}$ in the crystal formation as there are two VFT temperatures.

Experimentally, the first-crystallization temperature occurs when cooling the glass-forming melt at a lesser rate than the critical one, down to a temperature that is higher than the homogeneous nucleation temperature and is generally induced by intrinsic heterogeneous crystals which reduce the energy barrier for crystal growth. The isothermal crystallization time depends on overheating and undercooling temperatures and leads to a time-temperature-transformation diagram induced by intrinsic nuclei. The nose temperature of this diagram depends on the overheating temperature, the surviving crystal size and the energy saving $\varepsilon_{1 s}$.

The second nucleation temperature is lower and gives rise by homogeneous nucleation to imperfect crystals having an energy barrier for diffusion from the melt to the crystal slightly smaller than the first. The free-volume disappearance temperature of the undercooled melt decreases from $\mathrm{T}_{0 \mathrm{~m}}$ to $\mathrm{T}_{0 \mathrm{~g}}$. A glass state is obtained by quenching the melt using a cooling rate larger than its critical value. The vitreous transition temperature $\mathrm{T}_{\mathrm{g}}$ occurs at a homogeneous nucleation maximum-rate temperature determined by a smaller value $\varepsilon_{\operatorname{lgs}}\left(\theta_{\mathrm{g}}\right)$ of the energy saving associated with a smaller VFT temperature. The relaxation time leading to vitreous state is the time lag for initial formation of a homogeneously-nucleated-cluster distribution during the transient nucleation. These entities could be imperfect crystals. Their formation is a preliminary step during the long time leading to crystallization. The time dependence of various properties depends on the time lag $\tau^{\mathrm{ns}}$ associated to the transient nucleation and to the steady-state nucleation time $t_{\mathrm{sn}}$ depending on the energy barrier for crystal growth.

The model used in this paper is also based on previous publications related to the classical Gibbs free energy change for a crystal formation in an undercooled melt that has been completed by an energy saving associated with the equalization of Fermi energies or chemical potentials of melt and nascent crystal. This analysis only works for nascent crystals in an out-of-equilibrium state having a radius smaller than the critical radius for crystal growth because J. W. Gibbs's phase coexistence rule predicts the absence of energy saving for radii larger than the critical one when solid and liquid phases are at equilibrium at the melting temperature.

\section{Conclusions}

The vitreous transition is a new type of phase transition from undercooled melt to frozen state, without entropy and enthalpy change occurring at a temperature $\mathrm{T}_{\mathrm{g}}^{*}$, which corresponds to the maximum nucleation rate temperature of homogeneously-nucleated crystals in bulk metallic and non-metallic glass-forming melts. Because of the melt freezing, the steady-state nucleation time is too 
long to ever reach the divergence of the correlation length in critical phenomenon and the crystal's growth.

These nascent crystals would be formed with a free energy change which differs from the classical Gibbs free energy change used in many nucleation models. A complementary energy saving exists which depends on the atom or molecule number $n$ involved in these crystals. We have shown the existence of two homogeneous nucleation temperatures associated with two energy savings, which follow scaling laws as a function of the vitreous transition temperature. The nascent crystals acting at the vitreous transition could contain a lot of unoccupied ionic sites as compared with crystals surviving in the melt and acting as growth nuclei at higher temperatures.

The glass freezing occurs without entropy and enthalpy changes; these changes can only appear at unattainable times when crystallization occurs. This analysis shows that the frozen and the solid states have the same equilibrium specific heat below the glass transition, eliminating all speculations about other configurational contributions and phase transitions.

The disappearance temperature of the fully-relaxed enthalpy, as described in previous publications, does not depend on time and is equal to the thermodynamic temperature $\mathrm{T}^{*}$ g. The specific heat jump accompanying this phase transition is deduced from the linear variation of the relaxed enthalpy with temperature. The DSC runs are not able to detect $\mathrm{T}^{*} \mathrm{~g}$ because the enthalpy is continuous at this temperature.

The existence of a vitreous transition viewed as a constant of material was initially established by experiments eight years ago and published by the University of Pardubice.

\section{Acknowledgements}

This work was also sponsored by the sino-french Laboratory for the Application of Superconductors and Magnetic Materials involving the Northwest Institute for Non-ferrous Metal Research (NIN), the Northwestern Polytechnical University (NPU) in Xi'an (P.R. China). Thanks are due to Lian Zhou for NIN support as, Jean Etourneau, Philippe Odier, Jean-Louis Soubeyroux, Jean-Louis Tholence for their suggestions or their criticisms, Dr Jinna Mei from NPU and J.L. Soubeyroux for fully-relaxed enthalpy measurements of some glass-forming melts [75].

\section{References}

1. Zarzycki, J. Les Verres et l'Etat Vitreux; Masson: Paris, France, 1982.

2. Gutzov, I.; Schmeltzer, J. The Vitreous State; Springer-Verlag: Berlin, Germany, 1995.

3. Angell, C.A. Formation of glasses from liquids and biopolymers. Science 1995, 267, 1924-1935.

4. Berthier, L.; Biroli, G.; Bouchaud, J.; Cipelletti, L.; Masri, D.E.; L’Hôte, D.; Ladieu, F.; Pierno, M. Direct experimental evidence of a growing length scale accompanying the glass transition. Science 2005, 310, 1797-1800.

5. Tanaka, H.; Awasaki, T.; Shintani, H.; Watanabe, K. Critical-like behavior of glass-forming liquids. Nature Mater. 2010, 9, 324-331.

6. Kauzmann, W. The nature of the glassy state and the behavior of liquids at low temperatures. Chem. Rev. 1948, 43, 219-256. 
7. Liu, C.-Y.; He, J.; Keunings, R.; Bailly, C. New linearized relation for the universal viscosity-temperature behavior of polymer melts. Macromolecules 2006, 39, 8867-8869.

8. Williams, M.L.; Landel, R.F.; Ferry, J.D. Temperature dependence of relaxation mechanisms in amorphous polymers and other glass-forming melts. J. Am. Chem. Soc. 1955, 77, 3701-3707.

9. Takeuchi, A.; Kato, H.; Inoue, A. Vogel-Fulcher-Tammann plot for viscosity scaled with temperature interval between actual and ideal glass transitions for metallic glasses in liquid and supercooled liquid states. Intermetallics 2010, 18, 406-411.

10. Doolittle, A.K. Studies in Newtonian Flow. II. The dependence of the viscosity of liquids on free-space. J. Appl. Phys. 1951, 22, 1471-1475.

11. Ramachandrarao, P.; Dubey, K.S. A thermodynamic approach to the viscous behaviour of glass-forming liquids. Mat. Sc. Eng. B 1995, 32, 285-293.

12. Gibbs, J.H.; DiMarzio, E.A. Nature of the glass transition and the glassy state. J. Chem. Phys. 1958, 28, 373-383.

13. Holubovà, J.; Cernozek, Z.; Cernoskovà, E. The study of the glass transition by the stepscan DSC technique. J. Optoelectron. Adv. Mat. 2005, 7, 2671-2676.

14. Tournier, R.F. Crystal growth nucleation and Fermi energy equalization of intrinsic spherical nuclei in glass-forming melts. Sci. Technol. Adv. Mater. 2009, 10, 014607:1-014607:12.

15. Tournier, R.F. Crystal nucleation and equalization of Fermi energies of intrinsic nuclei and glass-forming melts. J. Phys. Confer. Ser. 2009, 144, 012116:1-012116:4.

16. Tournier, R.F. Presence of intrinsic growth nuclei in overheated and undercooled liquid elements. Phys. B 2007, 392, 79-93.

17. Vinet, B.; Magnusson, L.; Fredriksson, H.; Desré, P.J. Correlations between surface and interface energies with respect to crystal nucleation. J. Coll. Interf. Sci. 2002, 255, 363-374.

18. Turnbull, D.; Cech, R.E. Microscopic observation of the solidification of small metal droplets. J. Appl. Phys. 1950, 21, 804-810.

19. Bosio, L.; Defrain, A.; Epelboin, I. Changements de phase du gallium à la pression atmosphérique. J. Phys. France 1966, 27, 61-71.

20. Hays, C.C.; Johnson, W.L. Undercooling of bulk metallic glasses processed by electrostatic levitation. J. Non-Cryst. Solids 1999, 250-252, 596-600.

21. Tournier, R.F. Expected properties of gold melt containing intrinsic nuclei. In Proceedings of the 6th International Conference on Electromagnetic Processing of Materials, EPM 2009, Dresden, Germany, 19-23 October 2009; pp. 304-307.

22. Tournier, R.F. Undercooling versus Overheating of Liquid Elements Containing Intrinsic Nuclei: Application to Magnetic Texturing. Presented at the 4th International Workshop on Materials Analysis and Processing in Magnetic Fields Organized by Hamid Garmestani, Atlanta, GA, USA, 10-12 May 2010.

23. Tournier, R.F. Nucleation of crystallization in titanium and vitreous state in glass-forming melt. In Proceedings of the 12th World Conference on Titanium, Beijing, China, 19-24 June 2011.

24. Hirata, A.; Hirotsu, Y.; Ohkubo, T.; Hanada, T.; Bengus, V.Z. Compositional dependence of local atomic structures in amorphous $\mathrm{Fe}_{\mathrm{e} 100-\mathrm{xBx}}$ alloys studied by electron diffraction and high-resolution electron microscopy. Phys. Rev. B 2006, 74, 214206:1-214206:9. 
25. Sidorov, V.; Popel, P.; Calvo-Dahlborg, M.; Dahlborg, U.; Manov, V. Heat treatment of iron-based melts before quenching. Mater. Sc. Eng. A 2001, 304-306, 480-486.

26. Kokshenev, V.B. Characteristic temperatures of liquid-glass transition. Phys. A 1999, 262, 88-97.

27. Busch, R.; Liu, W.; Johnson, W.L. Thermodynamics and kinetics of the $\mathrm{Mg}_{65} \mathrm{Cu}_{25} \mathrm{Y}_{10}$ bulk metallic glass forming liquid. J. Appl. Phys. 1998, 83, 4134-4441.

28. Shadowspeaker, L.; Busch, R. On the fragility of Nb-Ni-based and Zr-based bulk metallic glasses. Appl. Phys. Lett. 2004, 85, 2508-2510.

29. Lu, I.-R.; Görler, G.P.; Willnecker, R. Specific volume of glass-forming liquid $\mathrm{Pd}_{43} \mathrm{Cu}_{27} \mathrm{Ni}_{10} \mathrm{P}_{20}$ and related thermodynamic aspects of the glass transition. Appl. Phys. Lett. 2002, 80, 4534-4536.

30. Yavari, A.R.; Le Moulec, A.; Nishiyama, N.; Inoue, A.; Vaughan G.; Kvick, A.; Botta, W.J. Glass Transition $\mathrm{T}_{\mathrm{g}}$ and quenched-in free volume in bulk metallic glasses measured by $X$-ray diffraction. J. Metast. Nanocryst. Mater. 2004, 20-21, 23-28.

31. Nishiyama, N.; Inoue, A. Glass transition behavior and viscous flow working of $\mathrm{Pd}_{40} \mathrm{Cu}_{30} \mathrm{Ni}_{10} \mathrm{P}_{20}$ amorphous alloy. Mater. Trans. JIM 1999, 40, 64-71.

32. Dubey, K.S.; Ramachandrarao, P.; Lele, S. Thermodynamic and viscous behavior of undercooled liquids. Thermochim. Acta 1996, 280/281, 25-62.

33. Kouamé, N.; Sei, J.; Houphouët-Boigny, D.; Kra, G.; Jumas, J.C.; Olivier-Fourcade, J. Propriétés thermiques et optiques des verres du système $\mathrm{Sb}_{2} \mathrm{~S}_{3}-\mathrm{As}_{2} \mathrm{~S}_{3}$. C. R. Chimie 2007, 10, 498-501.

34. Birge, N.O. Specific heat spectroscopy of glycerol and propylene glycol near the glass transition. Phys. Rev. B. 1986, 34, 1631-1642.

35. Schönhals, A.; Kremer, F.; Hofmann, A.; Fischer, E.W. Anomalies in the scaling of the $\alpha$-relaxation studied by dielectric spectroscopy. Phys. A 1993, 201, 263-269.

36. Mishra, R.K.; Dubey, K.S. Glass-forming ability of materials: A thermodynamic approach. J. Non-Cryst. Sol. 2009, 355, 2199-2204.

37. Yang, Z.; Lam, C.H.; Dimasi, E.; Bouet, N.; Jordan-Sweet, J.; Tsui, O.K.C. Method to measure the viscosity of nanometer liquid films from the surface fluctuations. Appl. Phys. Lett. 2009, 94, 251906:1-251906:3.

38. Lu, I.-R.; Wilde, G.; Görler, G.P.; Willnecker, R. Thermodynamic properties of Pd-based glass-forming alloys. J. Non-Cryst. Sol. 1999, 250-252, 577-581.

39. Schroers, J. On the formability of bulk metallic glass in its supercooled liquid state. Acta Mater. 2008, 56, 471-478.

40. Johari, G.P. Heat capacity and entropy of an equilibrium liquid from $\mathrm{T}_{\mathrm{g}}$ to $0 \mathrm{~K}$, and examining the conjectures of an underlying thermodynamic transition. Chem. Phys. 2001, 265, 217-231.

41. Henderson, D.W.; Ast, D.G. Viscosity and crystallization kinetics of $\mathrm{As}_{2} \mathrm{Se}_{3}$. J. Non-Cryst. Sol. 1984, 64, 43-70.

42. Waniuk, T.A.; Busch, R.; Masuhr, A.; Johnson, W.L. Equilibrium viscosity of the $\mathrm{Zr}_{41.2} \mathrm{Ti}_{13.8} \mathrm{Cu}_{12.5} \mathrm{Ni}_{10} \mathrm{Be}_{22.5}$ bulk metallic glass-forming liquid and viscous flow during relaxation, phase separation, and primary crystallization. Acta Mater. 1998, 46, 5229-5236.

43. Lu, Z.P.; Li, Y.; Liu, C.T. Glass-forming tendency of bulk La-Al-Ni-Cu-(Co) metallic glass-forming melts. J. Appl. Phys. 2003, 93, 286-290.

44. Lu, Z.P.; Liu, C.T. A new glass-forming ability criterion for bulk metallic glasses. Acta Mater. 2002, 50, 3501-3512. 
45. Lu, Z.P.; Li, Y.; Ng, S.C. Reduced glass transition temperature and glass forming ability of bulk glass forming alloys. J. Non-Cryst. Sol. 2000, 270, 103-114.

46. Angell, C.A.; Rao, K.J. Configurational excitations in condensed matter, and the "bond lattice" model for liquid-glass transition. J. Chem. Phys. 1971, 57, 470-481.

47. Hatase, M.; Hanaya, M.P.; Hikima, T.; Oguni, M. Discovery of homogeneous-nucleation-based crystallization in simple glass-forming liquid of toluene below its glass-transition temperature. J. Non-Cryst. Sol. 2003, 307-310, 257-263.

48. Kato, H.; Wada, T.; Hasegawa, M.; Saida, J.; Inoue, A. Fragility and thermal stability of Pt- and Pd-based bulk glass forming liquids and their correlation with deformability. Scripta Materialia 2006, 54, 2023-2027.

49. Kui, H.-W.; Turnbull, D. The heat capacity of $\mathrm{Ni}_{40} \mathrm{Pd}_{40} \mathrm{P}_{20}$ in the liquid, glass and crystallized states. J. Non-Cryst. Sol. 1987, 94, 62-69.

50. Legg, B.A.; Schroers, J.; Busch, R. Thermodynamics, kinetics, and crystallization of $\mathrm{Pt}_{57.3} \mathrm{Cu}_{14.6}$ $\mathrm{Ni}_{5.3} \mathrm{P}_{22.8}$ bulk metallic glass. Acta Mater. 2007, 55, 1109-1116.

51. Chen, H.S.; Goldstein, M. Anomalous visco-elastic behavior of metallic-glasses of Pd-Si-based alloys. J. Appl. Phys. 1972, 43, 1642-1648.

52. Mukherjee, S.; Schroers, J.U.; Zhou, Z.; Johnson W.L.; Rhim, W.-K. Viscosity and specific volume of bulk metallic glass-forming alloys and their correlation with glass-forming stability. Acta Mater. 2004, 52, 3689-3695.

53. Màlek, J.; Svoboda, R.; Pustkova, P.; Cicmanec, P. Volume and enthalpy relaxation of a-Se in the glass transition region. J. Non-Cryst. Sol. 2009, 355, 264-272.

54. Gallino, I.; Shah, M.B.; Busch, R. Enthalpy relaxation and its relation to the thermodynamics and crystallization of the $\mathrm{Zr}_{58.5} \mathrm{Cu}_{15.6} \mathrm{Ni}_{12.8} \mathrm{Al}_{10.3} \mathrm{Nb}_{2.8}$ bulk metallic glass-forming alloy. Acta Mater. 2007, 55, 1367-1376.

55. Meng, Q.G; Zhang, S.G.; Li, J.G.; Bian, X.F. Strong liquid behavior of $\operatorname{Pr}_{55} \mathrm{Ni}_{25} \mathrm{Al}_{20}$ bulk metallic glass. J. Alloys Compounds 2007, 431, 191-196.

56. Huang, H.J.; Shen, J.; Sun, X.B.; Yu, J.F. A new Ti-Zr-Hf-Cu-Ni-Si-Sn bulk amorphous alloy with high glass-forming ability. J. Alloys Compounds 2007, 427, 171-175.

57. Glade, S.C.; Johnson, W.L. Viscous flow of the $\mathrm{Cu}_{47} \mathrm{Ti}_{34} \mathrm{Zr}_{11} \mathrm{Ni}_{8}$ glass forming alloy. J. Appl. Phys. 2000, 87, 7249-7251.

58. He, S.; Liu, Y.; Huang, B.; Li, Z.; Wu, H. Effect of Zr on glass-forming ability and crystallization kinetics of $\mathrm{Y}_{56} \mathrm{Al}_{24} \mathrm{Co}_{20}$ metallic glass. J. Mater. Proc. Techn. 2008, 204, 179-183.

59. Zheng, Q.; Xu, J.; Ma, E. High glass-forming ability correlated with fragility of $\mathrm{Mg}-\mathrm{Cu}(\mathrm{Ag})-\mathrm{Gd}$ alloys. J. Appl. Phys. 2007, 102, 113519:1-113519:5.

60. Busch, R.; Bakke, E.; Johnson, W.L. Viscosity of the supercooled liquid and relaxation at the glass transition of the $\mathrm{Zr}_{46.75} \mathrm{Ti}_{8.25} \mathrm{Cu}_{7.5} \mathrm{Ni}_{10} \mathrm{Be}_{27.5}$ bulk metallic glass forming alloy. Acta Metall. 1998, 46, 4725-4732.

61. Zhang, B.; Wang, R.J.; Zhao, D.Q.; Pan, M.X.; Wang, W.H. Properties of Ce-based bulk metallic glass-forming alloys. Phys. Rev. B 2004, 70, 224208:1-224208:7.

62. Bian, X.F.; Sun, B.A.; Hu, L.N.; Jia, Y.B. Fragility of superheated melts and glass-forming ability in Al-based alloys. Phys. Lett. A 2005, 335, 61-67. 
63. Chen, H.; Turnbull, D.J. Evidence of a glass-liquid transition in gold-germanium-silicon. J. Chem. Phys. 1968, 48, 2560-2571.

64. Adam, G.; Gibbs, J.H. On the temperature dependence of cooperative relaxation properties in glass-forming liquids. J. Chem. Phys. 1965, 43, 139-146.

65. Turnbull, D.; Fisher, J.C. Rate of nucleation in condensed systems. J. Chem. Phys. 1949, 17, 71-73.

66. Cernosek, Z.; Holubova, J.; Cernoskova, E. Kauzmann temperature and the glass transition. J. Optoelectron. Adv. Mater. 2005, 7, 2941.

67. Cernosek, Z.; Holubova, J.; Cernoskova, E.; Liska, M. Enthalpic relaxation and the glass transition. J. Optoel. Adv. Mater. 2002, 4, 489-503.

68. Mehl, P.M. Determination of enthalpy relaxation times using traditional differential scanning calorimetry for glycerol and for propylene glycol. Thermochem. Acta 1996, 272, 201-209

69. Fransson, A.; Bäckström, G. Isothermal enthalpy relaxation of glycerol. Int. J. Thermophys. 1987, 8, 351-362.

70. Néel, L. Superparamagnétisme de grains très fins antiferromagnétiques. C. R. Am. Sci. 1961, 252, 4075-4080.

71. Wu, D.T.; Granasy, L.; Spaepen, F. Nucleation and the solid-liquid interfacial free energy. MRS Bulletin. Available online: http://www.mrs.org/publications/bulletin (accessed on December 2004).

72. Berton, A.; Chaussy, J.; Odin, J.; Rammal, R.; Tournier, R. Magnetocaloric investigation of (H,T) phase diagram of Cu-Mn spin glass. J. Physique-Lett. 1982, 43, L153-L158.

73. Tholence, J.L; Tournier, R. Susceptibility and remanent magnetization of a spin glass. J. Phys. Suppl. Coll. 1974, 35, C4:229-C4:235.

74. Mydosh, J.A. Spin Glasses: An Experimental Introduction; Taylor \& Francis: London, UK, 1993.

75. Mei, J.N.; Soubeyroux, J.L.; Blandin, J.J.; Li, J.S.; Kou, H.C.; Fu, H.Z.; Zhou, L. Structural relaxation of $\mathrm{Ti}_{40} \mathrm{Zr}_{25} \mathrm{Ni}_{8} \mathrm{Cu}_{9} \mathrm{Be}_{18}$ bulk metallic glass. J. Non-Cryst. Sol. 2011, 357, 110-115.

(C) 2011 by the authors; licensee MDPI, Basel, Switzerland. This article is an open access article distributed under the terms and conditions of the Creative Commons Attribution license (http://creativecommons.org/licenses/by/3.0/). 